RFP-4627

September 2, 1993

RFP-4627

September 2, 1993

\title{
JBK-75 STAINLESS STEEL MACHINABILITY STUDY
}

\author{
A. P. McManigle
}

A. W. Simonis

\section{¿SEERE ROCKY FLATS}

Rocky Flats Plant

P. O. Box 464

Golden, Colorado 80402-0464 


\section{DISCLAIMER}

This report was prepared as an account of work sponsored by an agency of the United States Government. Neither the United States Government nor any agency thereof, nor any of their employees, makes any warranty, expressed or implied, or assumes any legal liability or responsibility for the accuracy, completeness, or usefulness of any information, apparatus, product, or process disclosed, or represents that its use would not infringe privately owned rights. Reference herein to any specific commercial product, process, or service by trade name, trademark, manufacturer, or otherwise, does not necessarily constitute or imply its endorsement, recommendation, or favoring by the United States Government or any agency thereof. The view and opinions of authors expressed herein do not necessarily state or reflect those of the United States Government or any agency thereof.

This report has been reproduced directly from the best available copy.

Available to DOE and DOE contractors from the Office of Scientific and Technical Information, P. O. Box 62, Oak Ridge, TN 37831; prices available from (615) 576-8401, FTS 626-8401.

Available to the public from the National Technical Information Service, U.S. Department of Commerce, 5285 Port Royal Rd., Springfield, VA 22161. 
A. P. McManigle

A. W. Simonis

EG\&G ROCKY FLATS, INC.

ROCKY FLATS PLANT

P. O. BOX 464

GOLDEN, COLORADO $80402-0464$

\section{PREPARED UNDER CONTRACT DE-AC04-90DE62349 \\ FOR THE \\ ALBUQUERQUE OPERATIONS OFFICE \\ U.S. DEPARTMENT OF ENERGY}




\section{CONTENTS}

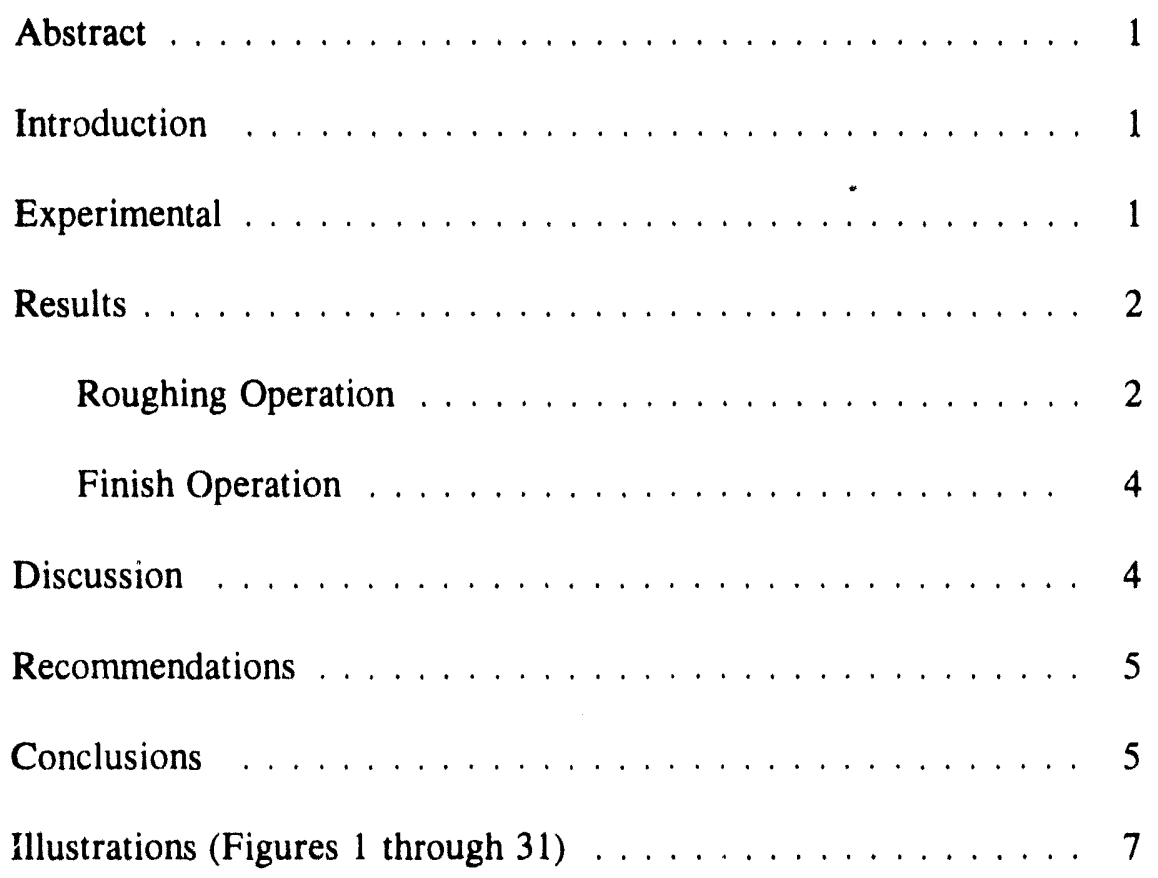




\title{
JBK-75 STAINLESS STEEL MACHINABILITY STUDY
}

\author{
A. P. McManigle and A. W. Simonis
}

\begin{abstract}
The Machining \& Gaging group at the Rocky Flats Plant performed a machinability study on JBK-75 stainless steel forgings. The study characterized machinability of the material by varying cutting speeds and feedrates utilizing four tools for the roughing operation and four tools for the semifinish operation. The tools tested were obtained from four manufacturers.
\end{abstract}

Twelve parts were machined utilizing an experimental design to determine all possible interactions between cutting speeds and feedrates. To evaluate the machinability of the material, quantitative measures in tool life, tool wear, surface finish, chip control, and material removal rates were analyzed.

The benefits gained from this study are: higher material removal rates, longer tool life, minimal tool :rear, improved chip control and reliability, increased productivity, and cost minimization.

\section{INTRODUCTION}

JBK-75 stainless steel has always been difficult to machine because of its extreme abrasiveness. The objective of this study was to find a cutting tool grade or number of grades that would be most applicable for this purpose. No prior machinability or insert grade application testing had been performed or documented.

Characterizing the material through a machinability study offers excellent advantages for future fabrication of components that require JBK-75 stainless steel. By experimenting with various cutting tools, insert grades, speeds, and feeds, we can determine quantitative measurements in tool life, wear, chip form, and surface finish. Machinability of a material is influenced by the tool material, tool geometry, cutting fluid, machining parameters, and properties of the workpiece material.

Most tools currently utilized to machine JBK-75 stainless steel display accelerated tool wear, poor tool life, and inadequate chip control. The surface scale on these JBK-75 components is difficult to remove, extremely abrasive, and produces a major portion of the tool wear. Abrasive action of the workpiece on the cutting tool is due to: (1) hard constituents contained in the microstructure of the material and (2) strain hardening induced in the chip and workpiece by the machining process.

Metallurgical characteristics of JBK-75 stainless steel forgings prior to machining include yield strength of $115 \mathrm{ksi}$, ultimate strength of $150 \mathrm{ksi}$, and Rockwell 90 Rb hardness. The alloying elements having the greatest effect on abrasiveness and machining ability of the material are: 13.516.0\% $\mathrm{Cr}$ and $29.0-31.0 \% \mathrm{Ni}$.

Four 35- and 80-degree diamond inserts were tested using various cutting speeds, feedrates, chip breakers, and grades. The tools tested wert manufactured by Carboloy, Kennametal, Teledyn: Firth Sterling, and Sandvik. A statistical design of experiments systematically varied the controlled cutting speeds and feedrates and analyzed the effects of these variables on the output. Statistical design of experiments is very beneficial in determining which process variables are influential on the output and at what levels the variables should be held to optimize process performance.

\section{EXPERIMENTAL}

A Leblond 12/12 Mark II CNC lathe was used for roughing and semi-finish operations. Twelve JBK-75 stainless steel forgings with rough surface scale on the inside and outside surfaces were 
utilized. The tools were tested on the side of the part requiring removal of the most material. The initial facing operation requires nine passes, and the outside surface and contour require 22 roughing passes at 0.030 inches depth-of-cut (DOC) with an 80-degree diamond insert. The semi-finish operation requires one pass on the face, outside surface, and contour at 0.005-in. DOC with a 35-degree diamond insert.

The tool holder used for roughing the face and outside contour is a Kennametal combination pin and clamping lock. This holder has a -5-degree back rake, side rake, and side cutting edge angles with +5 -degree end cutting edge, side relief, and end relief angles. The tool holder used for semifinishing the face and outside contour is another Kennametal combination pin and clamping lock with a -9-degree back rake angle, -5-degree side rake angle, -3-degree side cutting edge angle, 52degree end cutting edge angle, and +5-degree side and end relief angles.

Table 1 gives the manufacturers, grades, and operations for the cutting tools studied. The machining parameters were varied throughout the study, cutting speeds were 350 and 450 surface feet per minute (SFPM), and the feedrates were 0.008 and 0.012 in. per revolution (IPR) for roughing, and 0.003 and 0.006 IPR for finishing. Machining was performed wet with emulsion flood coolant using a Trim-Sol 50:1 concentration. Machining time is four min. for the roughing operation and $30 \mathrm{sec}$ for finishing. Tool wear, tool life, and surface finish data were recorded to analyze and evaluate machinability of the material. Surface finish was measured with a Pocket Surf III profilometer. Chip samples were taken for each insert to evaluate chip type and contrcl.

\section{RESULTS}

\section{Roughing Operation}

The four tools used for roughing were tested at several cutting speeds and feed rates. See Table 1.

\section{Carboloy 550}

The Carboloy 550 is a multi-coated $\mathrm{TiN}+\mathrm{TiC}+$ TiN carbide insert. Figures 1, 2, and 3 show these inserts after testing at the parameters shown in Table 1. Chip samples are displayed in Figure 4. The long stringy chip at the top of Figure 4 creates disposal problems, can mar the workpiece surface, and injure the operator. The type of chip shown in the midsection of Figure 4 is very manageable and safer for the operator. Short chips (bottom of photograph) are ideal-easy to manage and disposable.

\section{Teledyne MP26}

The Teledyne MP26 is a TiN-coated carbide insert. Figures 5, 6, and 7 show the inserts after testing. The chip sample at the top of Figure 8 is extremely hazardous and difficult to manage. The feathered or ragged edge in the middle chip was caused by the tool tearing the material from the workpiece instead of shearing it. The tearing is directly correlated with a dull or rough cutting edge (demonstrated in Figure 6). The C-type chip at the bottom of Figure 8 also shows feathering.

\section{Kennametal KC730}

The Kennametal KC730 is a TiN-coated carbide tool. Figures 9, 10, and 11 show these tools after testing. This insert produced acceptable results. The first insert produced a large helix spring-type chip (top of Figure 12). The connected C-type chip (middle, Figure 12) and the small fragments (bottom, Figure 12) were easy to manage and posed no hazard to the operator.

\section{Carboloy TP30}

The Carboloy TP30 is a multi-coated TiN + TiCN $+\mathrm{TiC}$ tool. These inserts after testing are shown in Figures 13, 14, and 15. This tool produced continuous snarling chips (top and middle, 
TABLE 1. Machining Parameters and Results

\begin{tabular}{|c|c|c|c|c|c|c|}
\hline \multirow[b]{2}{*}{ TOOLS } & \multirow{2}{*}{$\begin{array}{l}\text { SPEED } \\
\text { (SFPM) } \\
\end{array}$} & \multirow{2}{*}{$\begin{array}{l}\text { FEED } \\
\text { (IPR) }\end{array}$} & \multirow{2}{*}{$\begin{array}{l}\text { DOC } \\
\text { (in.) } \\
\end{array}$} & \multirow{2}{*}{$\begin{array}{c}\text { SF } \\
\text { (rms) } \\
\end{array}$} & \multicolumn{2}{|r|}{ IMPACT ON TOOLS } \\
\hline & & & & & Wear (in.) & Comments \\
\hline \multicolumn{7}{|c|}{ Roughing Operation } \\
\hline \multirow[t]{3}{*}{ Carboloy 550} & 350 & 0.008 & 0.030 & 54 & * & Chipping, edge buildup \\
\hline & 450 & 0.008 & 0.30 & 30 & 0.0056 & Moderate edge buildup \\
\hline & 450 & 0.012 & 0.30 & 115 & 0.008 & Edge buildup, chipping \\
\hline \multirow[t]{3}{*}{ Teledyne MP26 } & 350 & 0.008 & 0.30 & 26 & 0.007 & Chipping, odge buildup \\
\hline & 450 & 0.008 & 0.30 & 41 & + & Failure from excessive chipping \\
\hline & 450 & 0.012 & 0.30 & 84 & $*$ & Failure from excessive chipping \\
\hline \multirow[t]{3}{*}{ Kennametal KC730 } & 350 & 0.008 & 0.030 & 20 & 0.013 & Edge buildup \\
\hline & 450 & 0.008 & 0.030 & 15 & 0.0048 & Moderate edge buildup \\
\hline & 450 & 0.012 & 0.030 & 118 & * & Failure from chipping \& edge buildup \\
\hline \multirow[t]{3}{*}{ Carboloy TP30 } & 350 & 0.008 & 0.030 & 57 & $\bullet$ & Edge buildup, irregular depressions on cutting edge \\
\hline & 450 & 0.008 & 0.030 & 25 & 0.017 & Moderate edge buildup \\
\hline & 450 & 0.012 & 0.030 & $*$ & - & Failure from chipping \& edge buildup \\
\hline \multicolumn{7}{|c|}{ Finish Operation } \\
\hline \multirow[t]{3}{*}{ Teledyne TC+ } & 350 & 0.003 & 0.005 & 22 & 0.0068 & " \\
\hline & 450 & 0.003 & 0.005 & 16 & 0.0056 & \\
\hline & 450 & 0.006 & 0.005 & 67 & 0.0068 & Cratering on rake face \\
\hline \multirow[t]{3}{*}{ Kennametal KT125 } & 350 & 0.003 & 0.005 & 37 & 0.0068 & Chipping on cutting edge \\
\hline & 450 & 0.003 & 0.005 & 31 & 0.0056 & Moderute chipping \\
\hline & 450 & 0.006 & 0.005 & 65 & $\cdot$ & Excessive chipping on nose radius \\
\hline \multirow[t]{2}{*}{ Teledyne SD3 } & 450 & 0.003 & 0.005 & 48 & 0.003 & Moderate chipping \\
\hline & 450 & 0.006 & 0.005 & 63 & 0.0028 & Edge buildup and chipping \\
\hline \multirow[t]{3}{*}{ Sandvik MF435 } & 350 & 0.003 & 0.005 & 28 & 0.0068 & Coating deterioration on rake face \\
\hline & 450 & 0.003 & 0.005 & 35 & 0.0084 & Edge buildup and coating deterioration \\
\hline & 450 & 0.006 & 0.005 & 87 & 0.008 & Significant edge buildup and coating deterioration \\
\hline
\end{tabular}

- Not measureable because of cutting edge deterioration

- No dau available 
Figure 16) and a spring-type chip (bottom, Figure 16).

\section{Finish Operation}

Testing of 35-degree diamond inserts for finish operations was performed at cutting speeds and feedrates shown in Table 1.

\section{Teledyne TCt}

The Teledyne 332A is a coated carbide tool. Figures 17,18 , and 19 show these inserts after testing. This tool produced continuous snarling chips at all machining parameters (Figure 20).

\section{Kennemetal KT125}

The Kennemetal KT125 is a cermet tool with an ultra-fine chip breaker designed for small depth of cut. Figures 21, 22, and 23 show these inserts after testing. This tool produced helical-type chips at all machining parameters, but chips became shorter as cutting speed and feedrate increased (Figure 24).

\section{Teledyne SD3}

The Teledyne SD3 is also a cermet tool. The manufacturer specified that running this tool at cutting speeds less than 400 SFPM would cause premature failure. Figures 25 and 26 show effects of testing. At 450 SFPM and 0.005 DOC, the insert produced bird-nest-type chips at 0.003 IPR (top of Figure 27); however, when feedrate was increased to 0.006 , excellent chip control was obtained (bottom of Figure 27).

\section{Sandvik 435}

The Sandvik MF435 is a TiC, $\mathrm{Al}_{2} \mathrm{O}_{3}$, and TiN coated carbide tool. These inserts after testing are shown in Figures 28, 29, and 30. The bird-nest chips were produced on the first run (Figure 31); but when speed and feedrates were increased, spring-type chips were produced which were easy to manage and less hazardous (bottom of Figure 31).

\section{DISCUSSION}

Evaluation of the testing indicates that higher cutting speeds and lower feedrates provide better surface finishes and less wear. In all cases, surface finish and flank wear became worse as feedrates increased; and in some instances, catastrophic tool failure occurred. Also, surface finish and flank wear were generally worse at lower cutting speeds and feedrates.

Analysis of the data received from this study indicates that three 80-degree diamond inserts can be used successfully to rough machine JBK-75 stainless steel: Carboloy 550, Carboloy TP30, and Kennametal KC730 cutting tools. The Carboloy 550 insert provided less tool wear, longer tool life, better surface finish, and excellent chip control at a speed of 450 SFPM and feedrate of 0.008 IPR. The Kennametal KC730 insert also provided good results at these same machining parameters. The Carboloy TP30 produced a good surface finish at 450 SFPM and 0.008 IPR, but chip control was poor and flank wear was high.

For semi-finish or finish machining, three 35degree diamond inserts exhibited good performance and reliability: Teledyne TC + , Teledyne SD3, and Kennametal KT125. The Teledyne TC + carbide insert provided less wear and better surface finish at 450 SFPM and 0.003 IPR. The Kennametal KT 125 cermet insert exhibited acceptable chip control, less flank wear, and good surface finish at 450 SFPM and 0.003 IPR. The Teledyne SD3 cermet insert provided good results at a speed rate of 450 SFPM and feedrates of 0.003 and 0.006 IPR.

Evaluation of the information acquired from this study indicates that increasing cutting speed can improve surface finish and chip control, reduce tool wear, increase tool life, and improve productivity. Decreasing cutting speed reduces chip control, deteriorates surface finish, increases 
tool wear, and decreases tool life and productivity. Higher feedrates enhance chip control but increase tool wear, reduce tool life, and deteriorate surface finish. Lower feedrates improve surface finish and increase tool life, but do not always provide good chip control.

\section{RECOMMENDATIONS}

Based on the results of this study, the Rocky Flats Machining \& Gaging group recommends the Carboloy $\mathbf{5 5 0}$ carbide insert for rough machining JBK-75 stainless steel components. The insert should be run at a cutting speed of 450 SFPM and feedrates of 0.008 to 0.010 IPR to fully optimize the roughing operation for maximum productivity.

The Kennametal KC730 and Carboloy TP30 carbide inserts can also be utilized for rough machining JBK-75 stainless steel components. Recommended cutting speed and feedrates for these inserts are 450 SFPM and 0.008 IPR.

For semi-finish and finish machining of JBK-75 stainless steel, three 35-degree diamond inserts are recommended: Teledyne $\mathrm{TC}+$, Teledyne SD3, and Kennametal KT125. The Teledyne TC+ carbide insert should be run at a cutting speed of 450 SFPM and feedrate of 0.003 to 0.004 IPR. Recommended cutting speeds and feedrates for the Kennametal KT125 and Teledyne SD3 cermet inserts are: 500 SFPM or greater and 0.003 to 0.006 IPR. We recommend the Kennametal KT125 and Teledyne SD3 cermet inserts for semifinish and finish machining of JBK-75 stainless steel because higher cutting speeds and feedrates can be utilized and better surface finishes and chip control can be obtained.

\section{CONCLUSION}

Quantitative analysis of the test results from this study concludes that several inserts can be utilized to rough and finish machine JBK-75 stainless steel components. We found the Carboloy 550 carbide insert to be the most reliable tool for rough machining. It optimizes the machining operation by increasing tool life and productivity, reducing downtime, and improving chip control. The Kennametal KC730 and Carboloy TP30 carbide cutting tools are viable replacements for the rough machining operation and provide similar results.

We found the Teledyne SD3 and Kennametal KT125 cermet inserts to be the most reliable tools for semi-finish and finish machining of JBK-75 stainless steel components. They increase productivity because they can be run at higher cutting speeds, minimize operating costs, improve part surface finishes, and improve chip control. The Teledyne TC + carbide insert is an excellent replacement for semi-finish and finish machining this material.

Future work will involve testing of the Teledyne SD3 and Kennametal KT125 cermet inserts on 304L stainless steel components at cutting speeds near 700 and 800 SFPM. Other work involves machinability testing of tantalum/tungsten cases. Assorted tool materials will be tested utilizing various rake angle geometries and machining parameters. 
RFP-4627

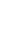



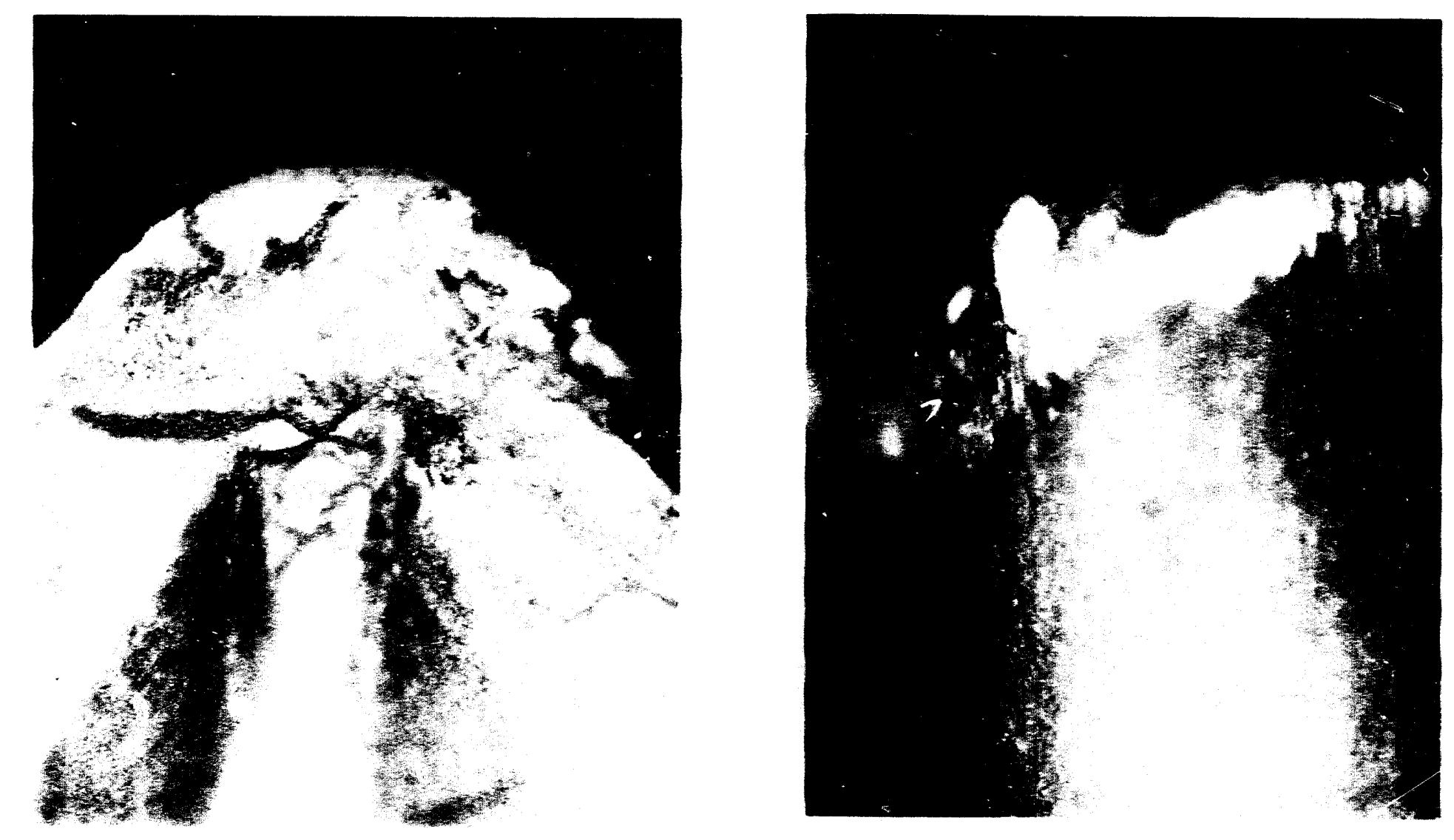

를

FIGURE 1. Carboloy 550 (350 SFPM, 0.008 IPR, 0.030 DOC) 

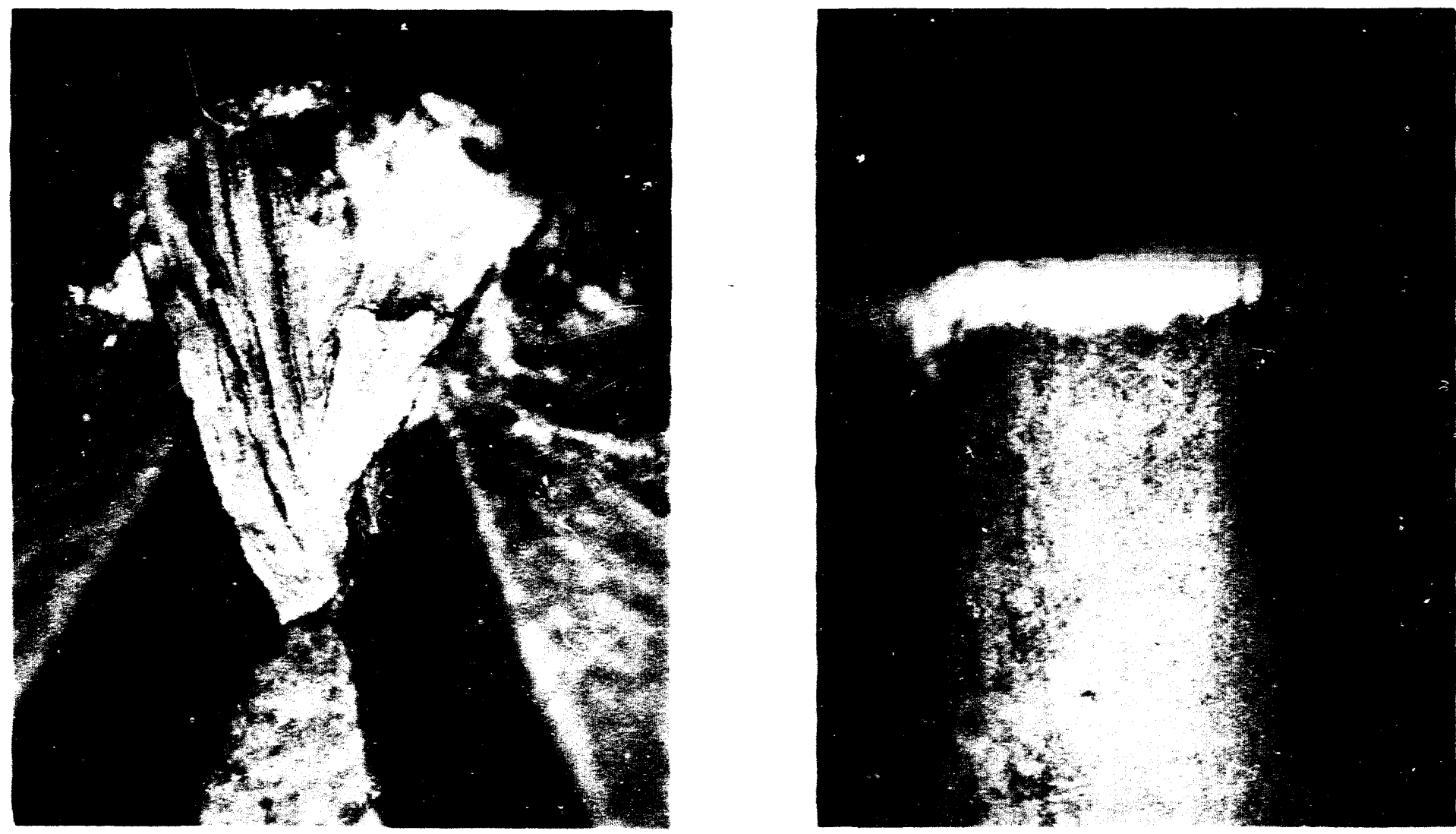

FIGURE 2. Carboloy 550 (450 SFPM, 0.008 IPR, and 0.030 DOC) 

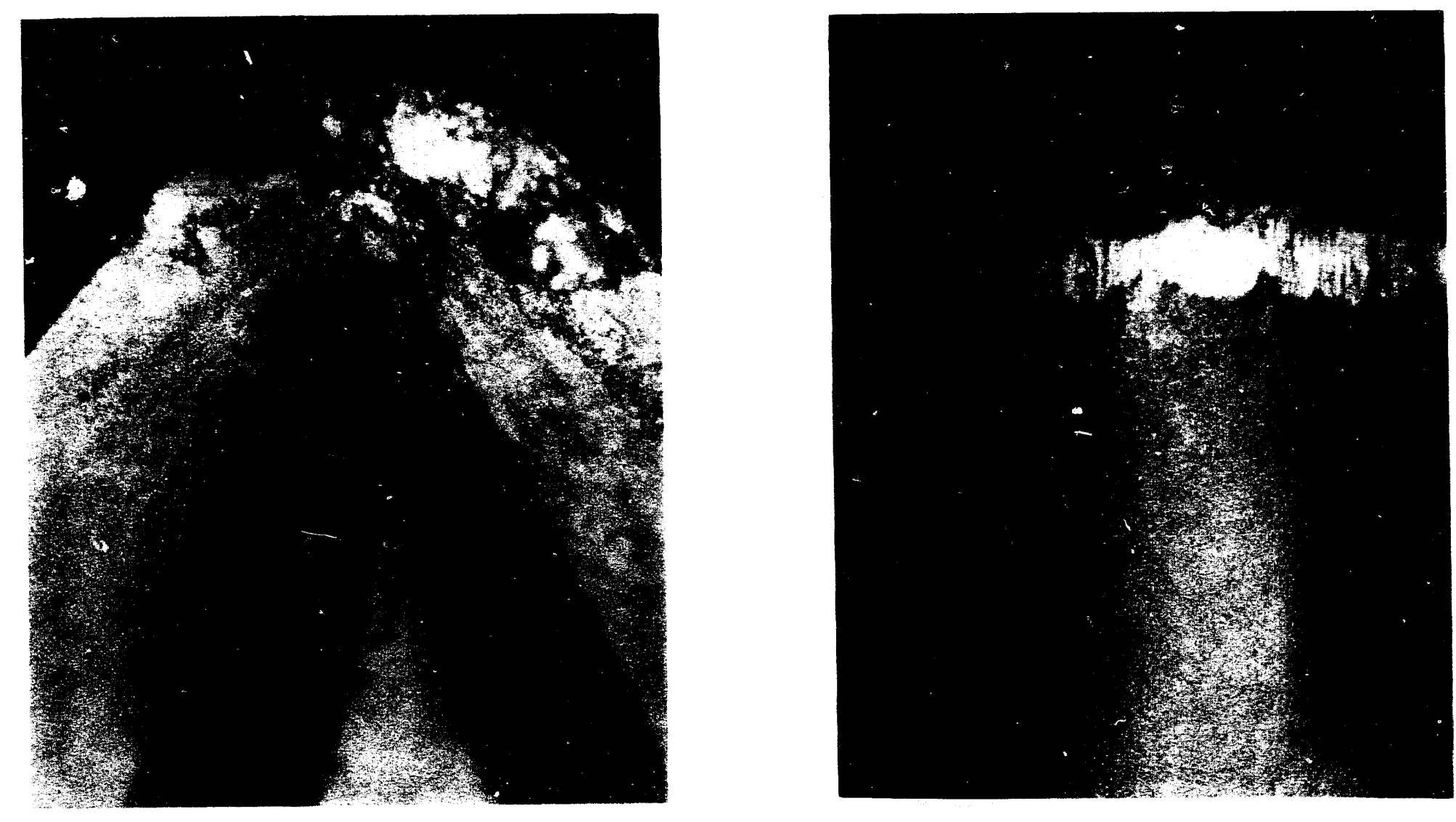

FIGURE 3. Carboloy 550 (450 SFPM, 0.012 IPR, and 0.030 DOC) 

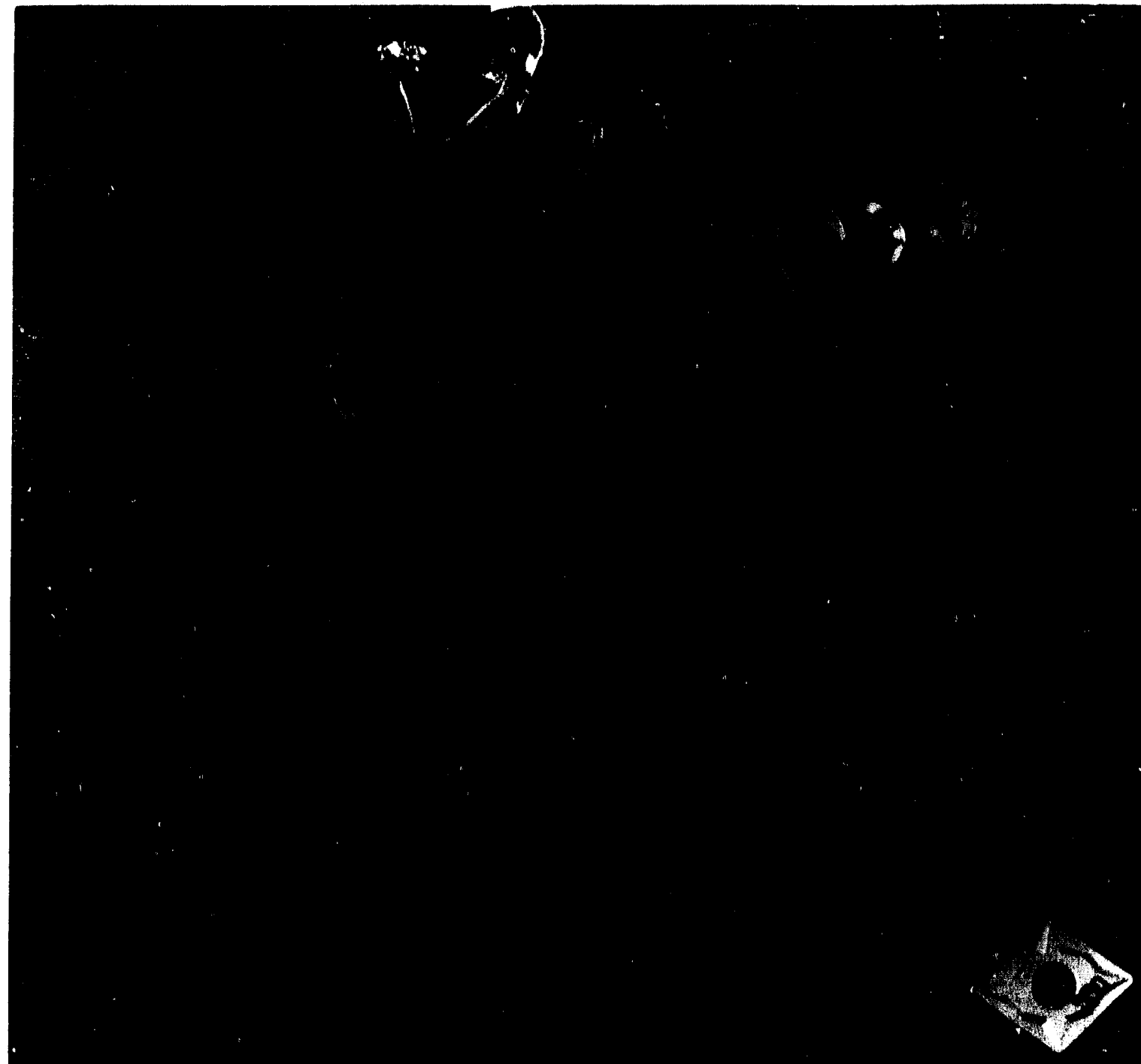

FIGURE 4. Chip Samples Produced by Carboloy 550 Inserts at Various Cutting Speeds and Feedrates and 0.030 DOC. Chips became shorter as speed and feed were increased. 


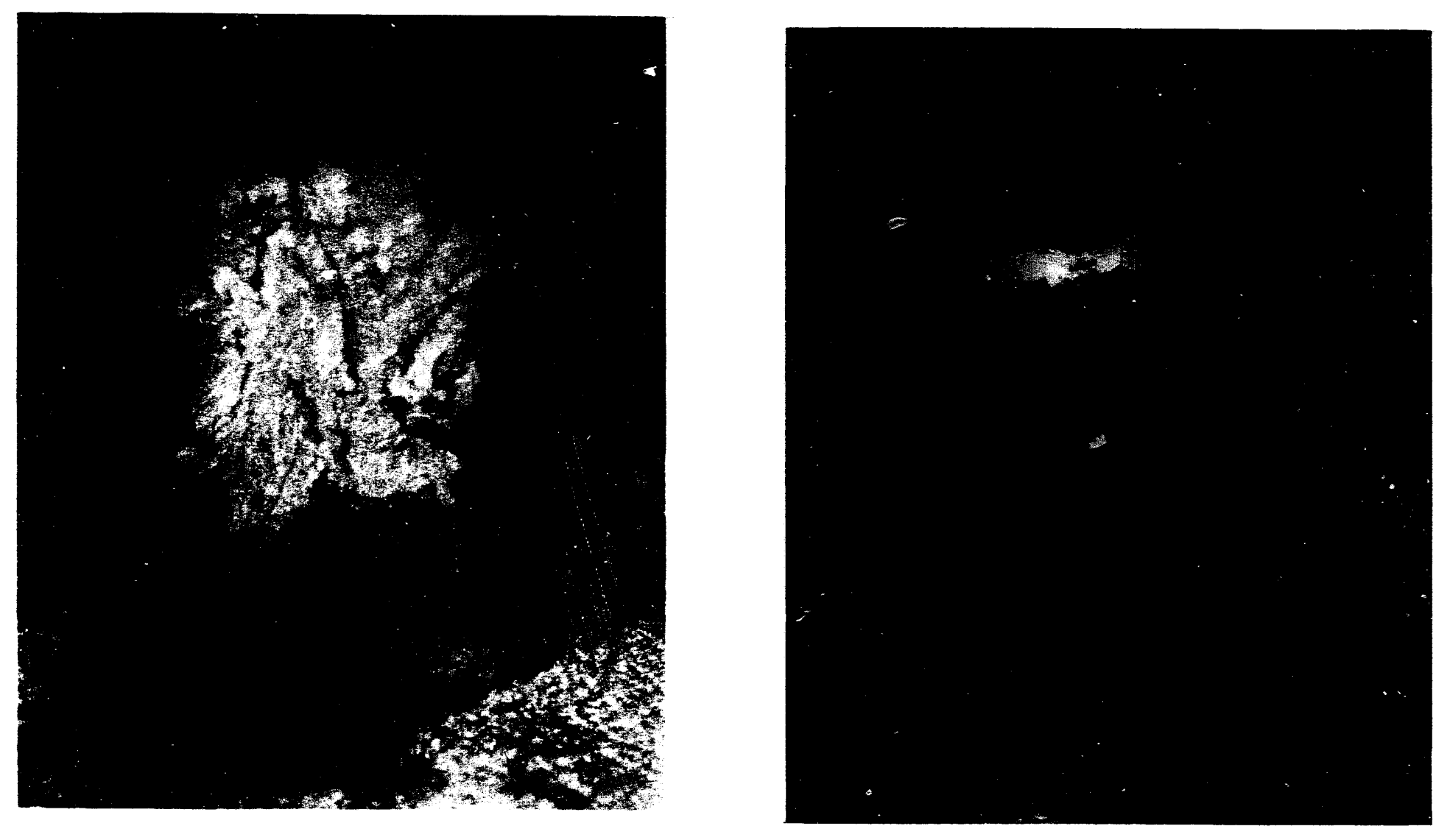

FIGURE 5. Teledyne MP26 (350 SFPM, 0.008 IPR, and 0.030 DOC) 

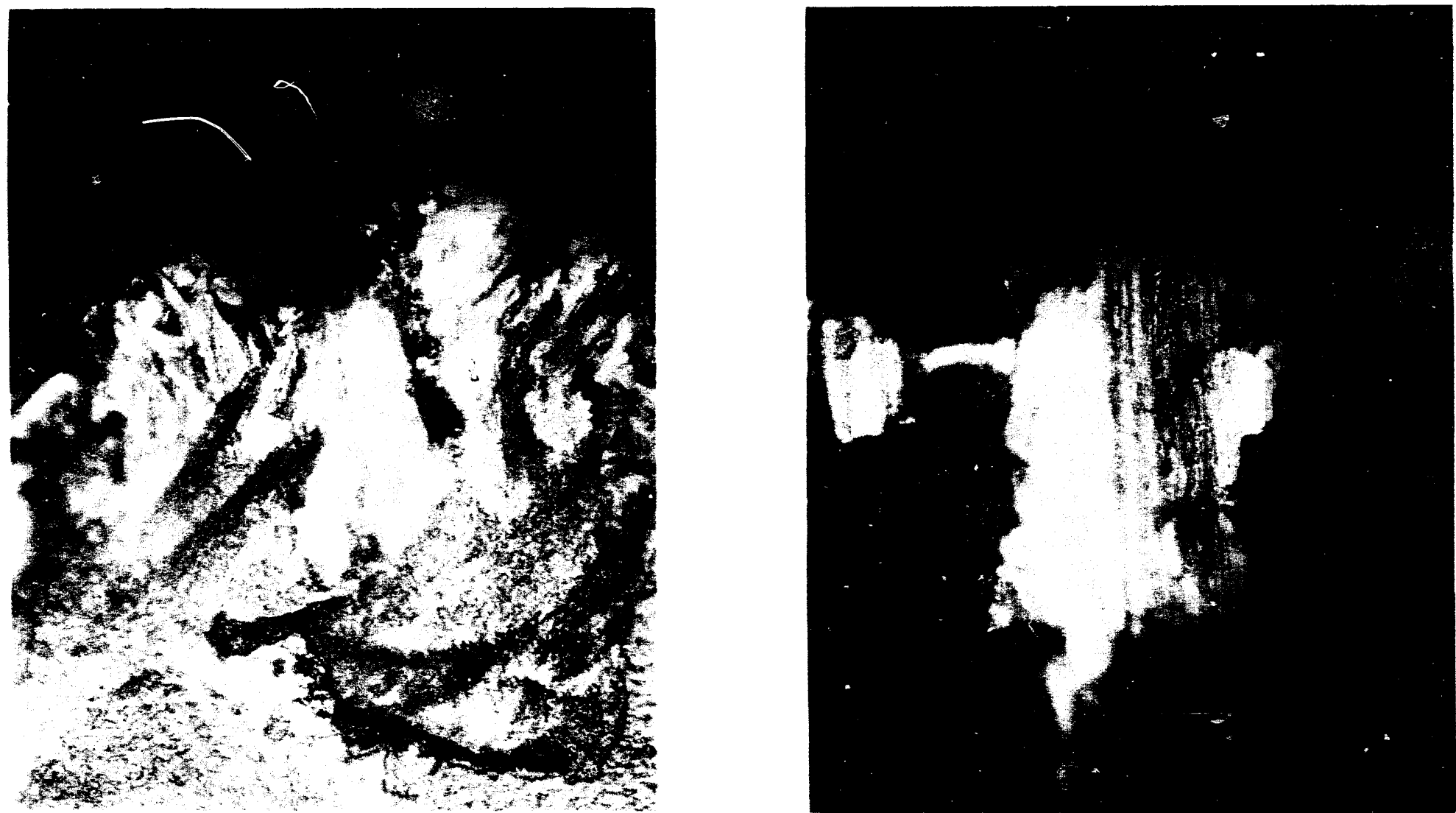

FIGURE 6. Teledyne MP26 (450 SFPM, 0.008 IPR, and 0.030 DOC) 

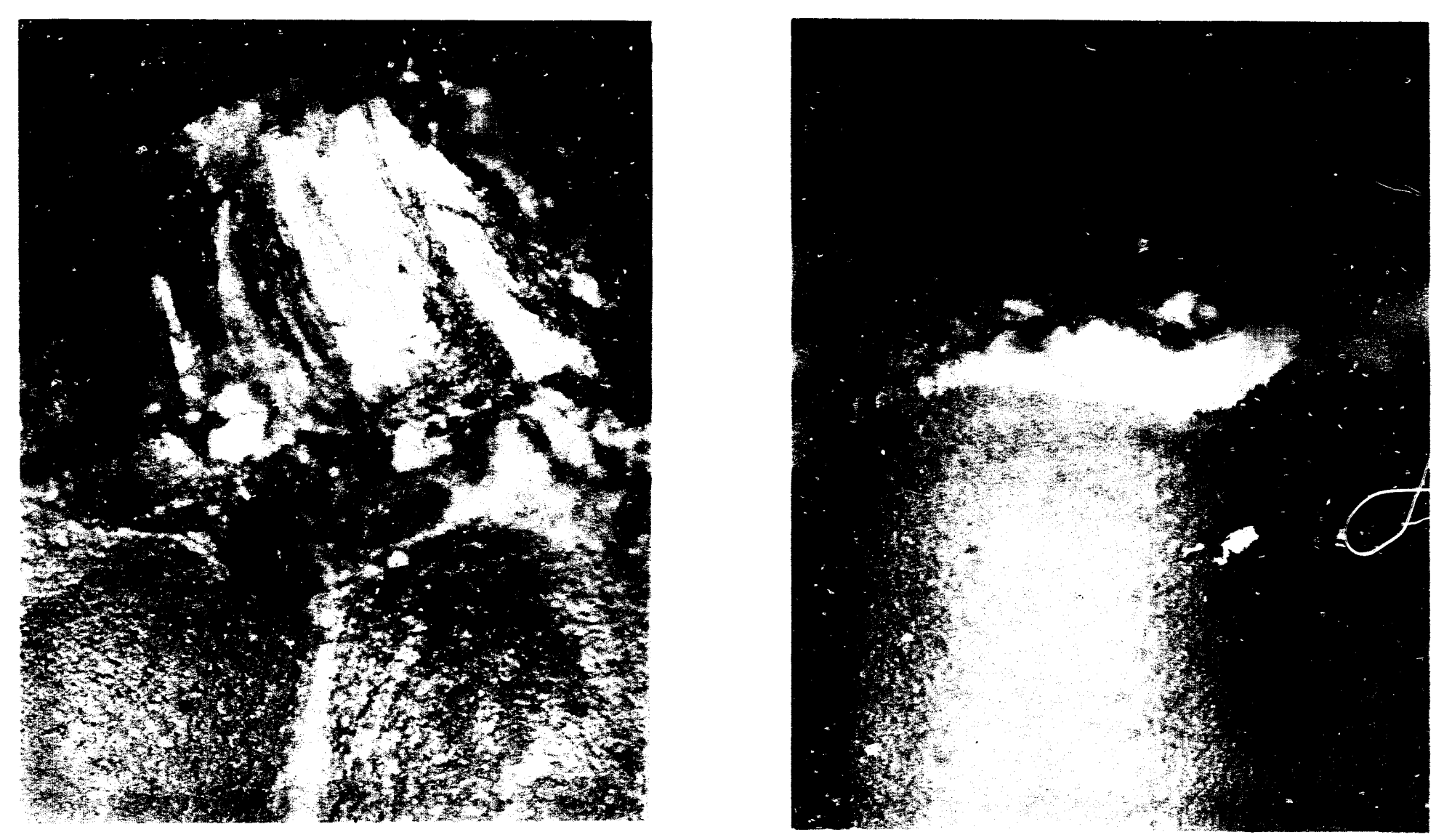

FIGURE 7. Teledyne MP26 (450 SFPM, 0.012 IPR, and 0.030 DOC) 


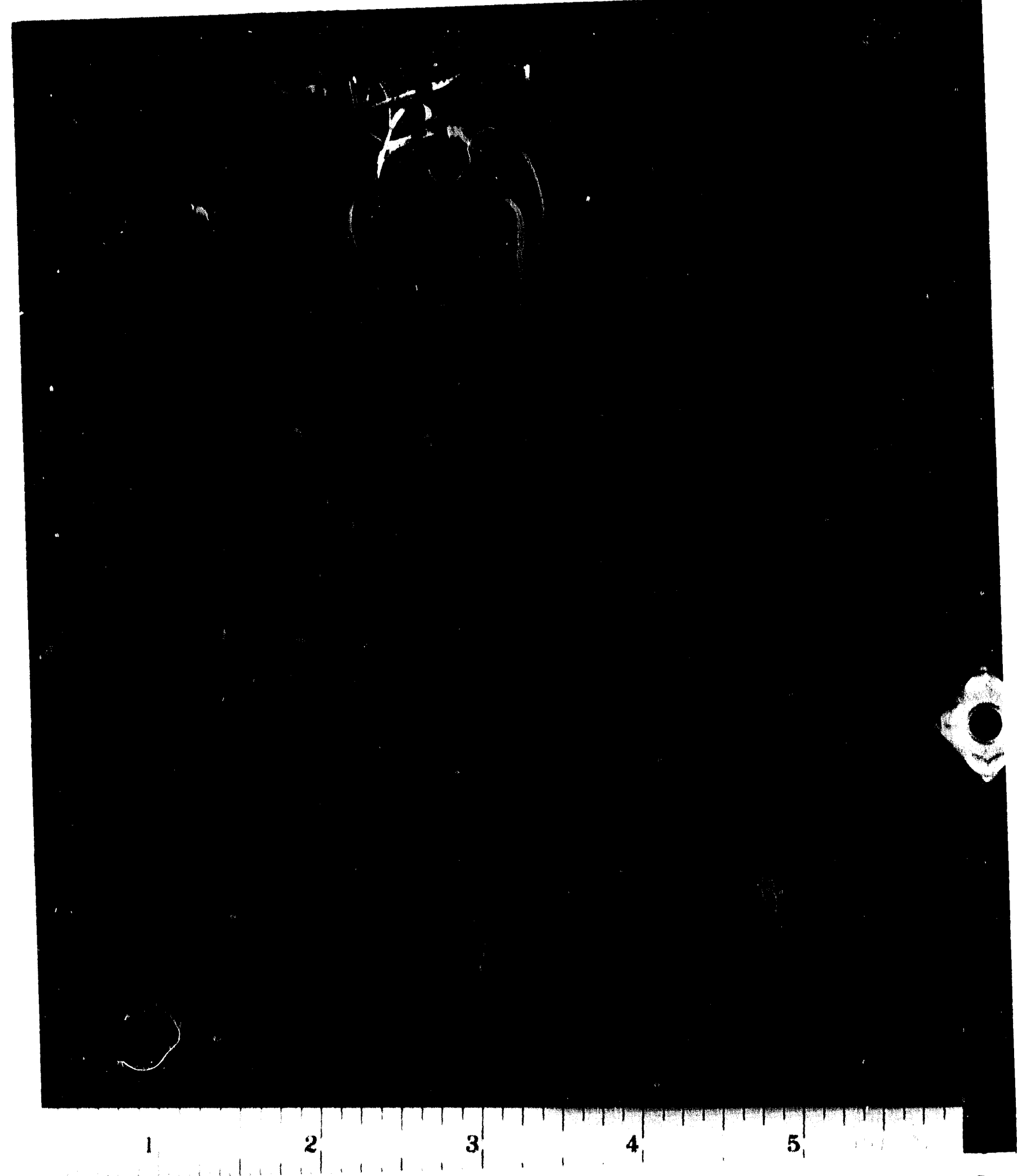

FIGURE 8. Chips Produced by Teledyne MP26 Inserts at Various Cutting Speeds and Feedrates and 0.030 DOC. Chips started to feather as speed and feed were increased and tool became dull. 

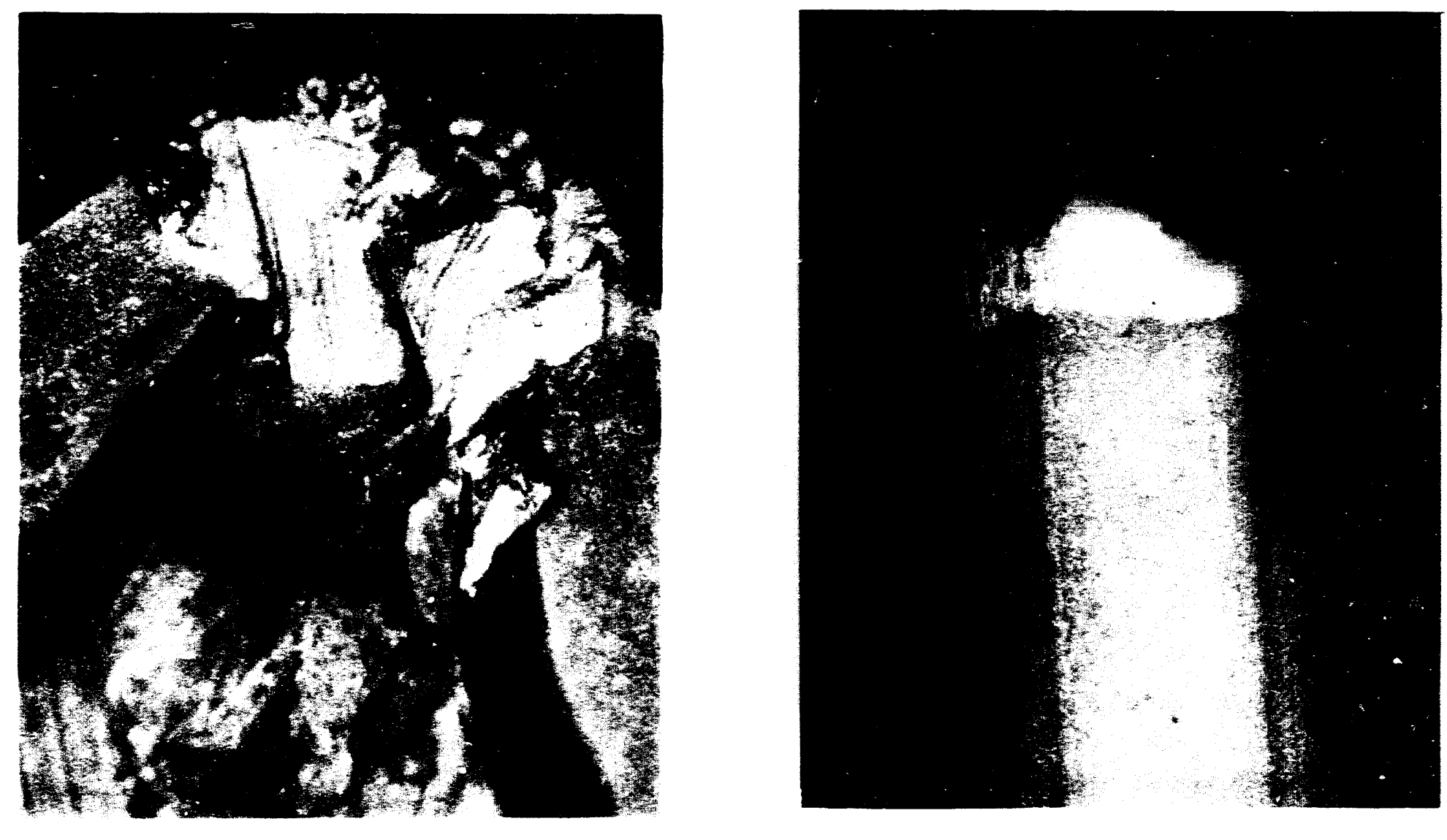

FIGURE 9. Kennametal KC730 (350 SFPM, 0.008 IPR, and 0.030 DOC) 

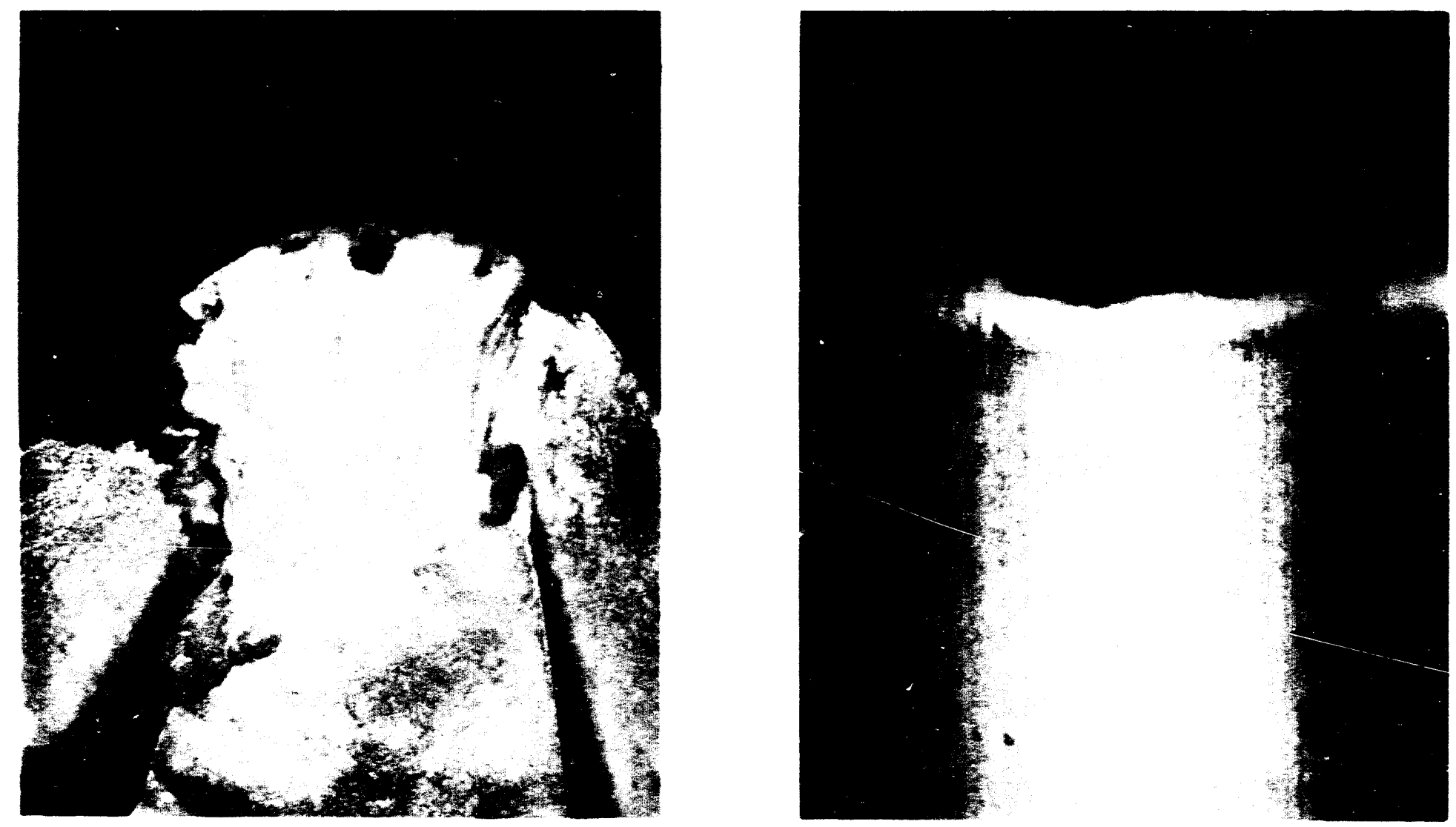

FIGURE 10. Kennametal KC730 (450 SFPM, 0.008 IPR, and 0.030 DOC) 

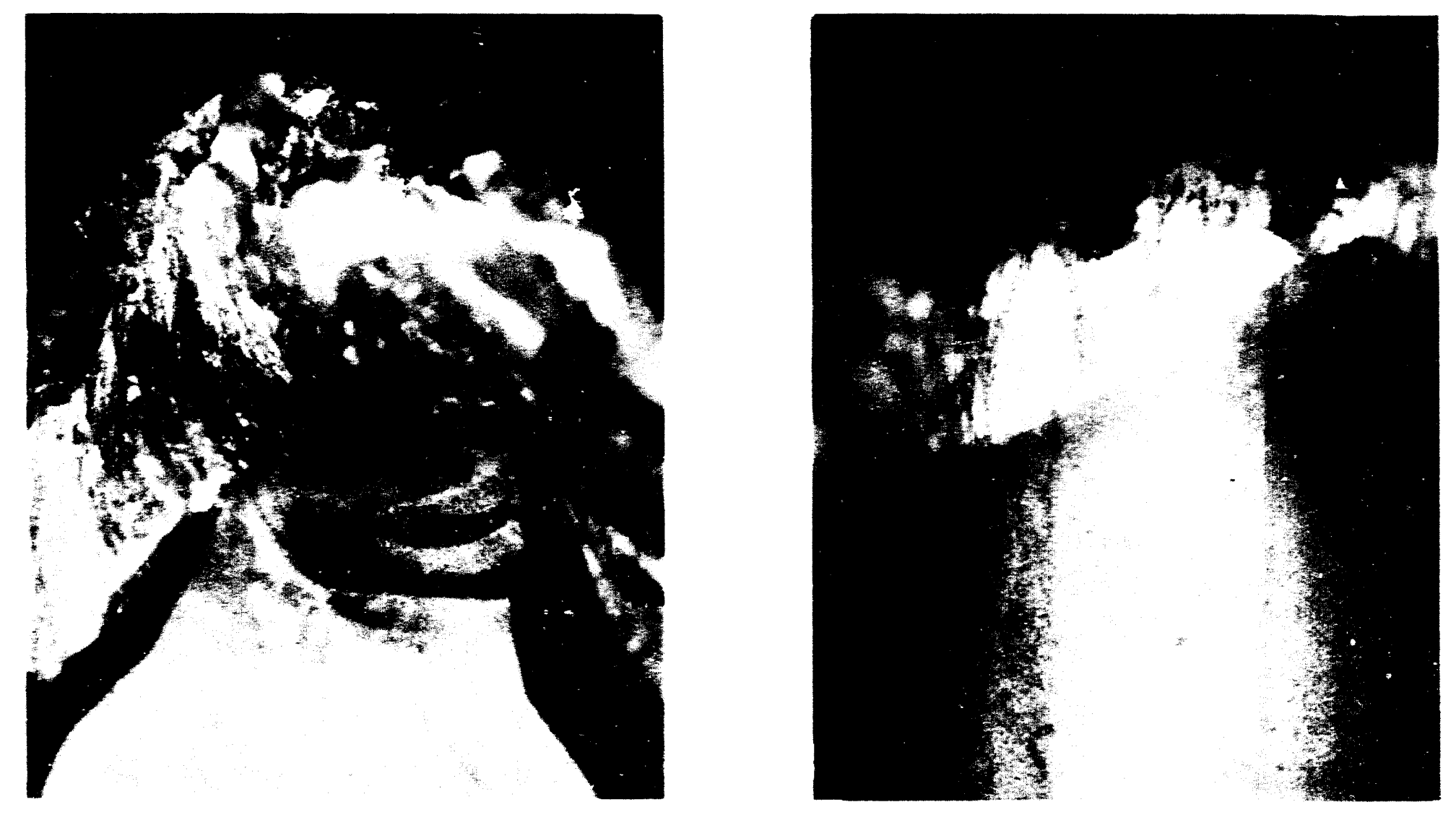

FIGURE 11. Kennametal KC730 (450 SFPM, 0.012 IPR, and 0.030 DOC) 


\section{RFP-4627}

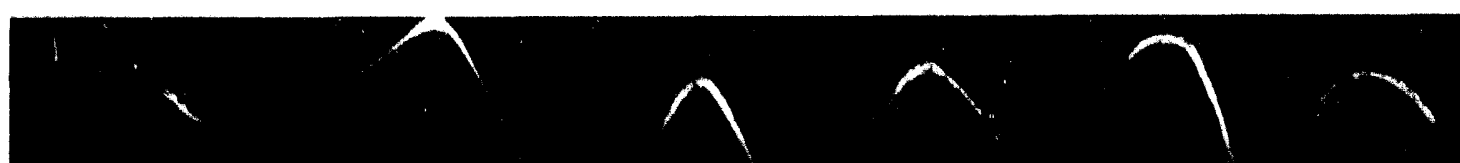

FIGURE 12. Chips Produced by Kennametal KC730 Inserts at Various Cutting Speeds and Feedrates and 0.030 DOC. Chips became more manageable at higher cutting speeds and feedrates. 

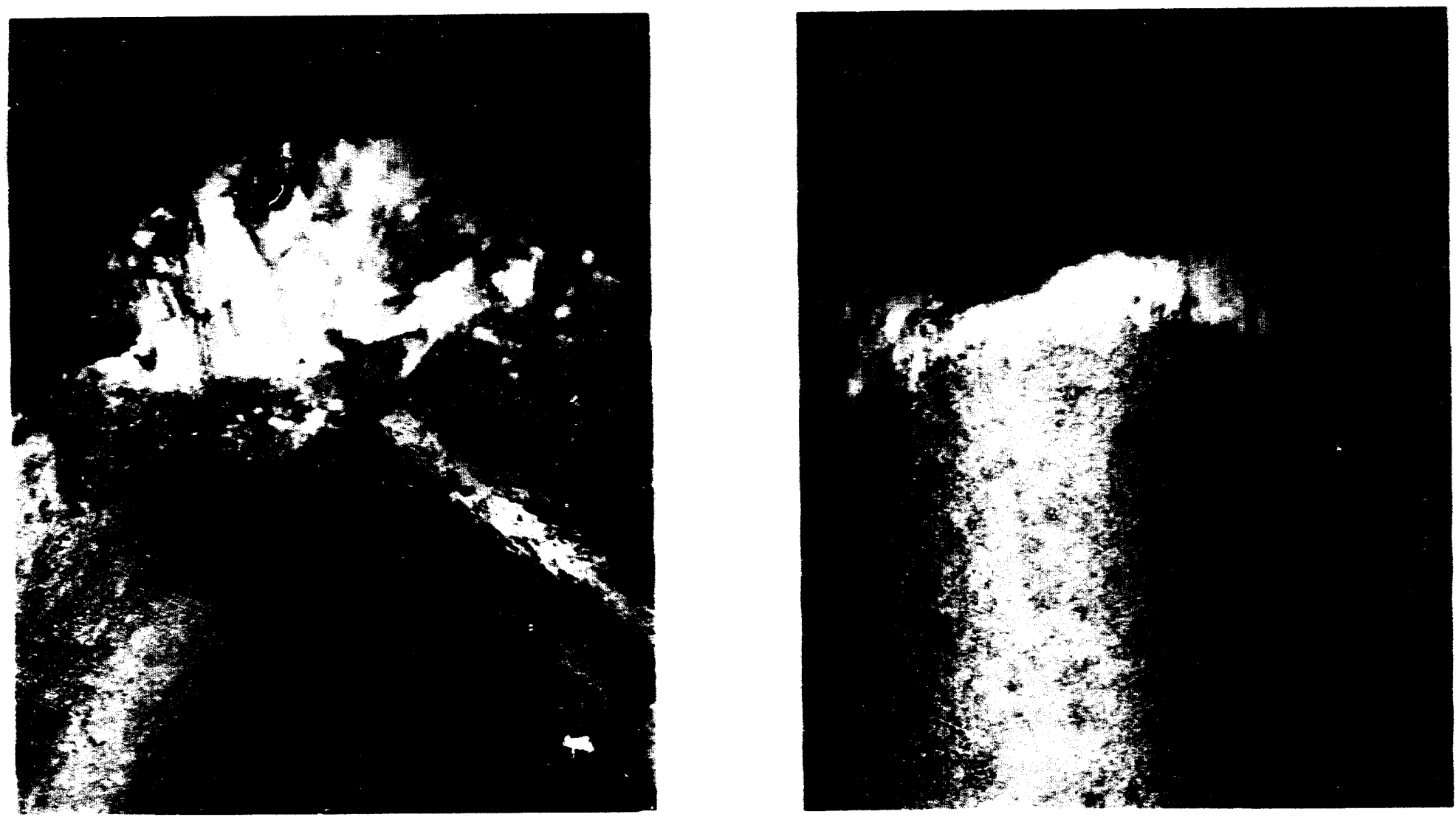

FIGURE 13. Carboloy TP30 (350 SFPM, 0.008 IPR, and 0.030 DOC) 

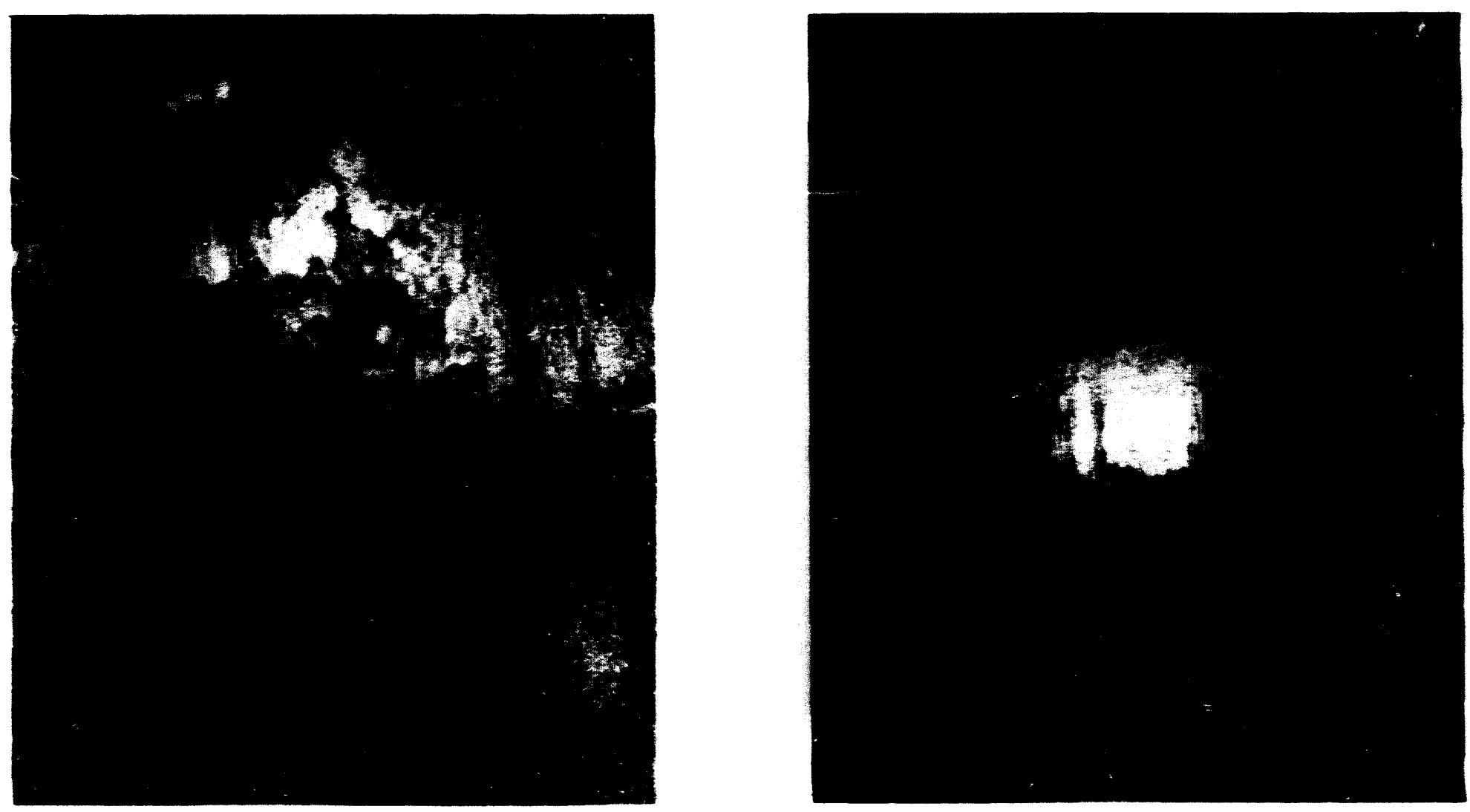

FIGURE 14. Carboioy TP30 (450 SFPM, 0.008 IPR, and 0.030 DOC) 

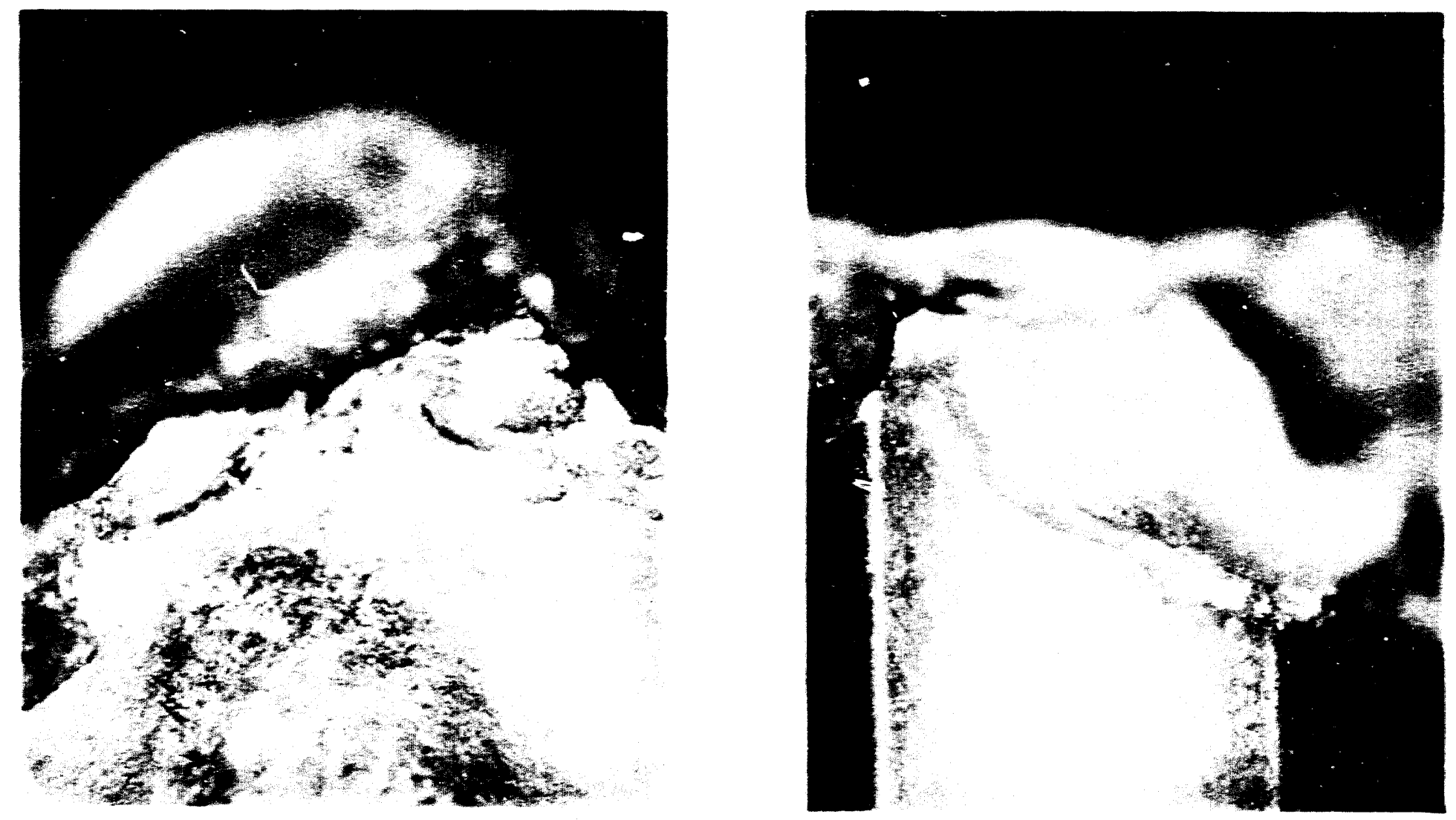

FIGURE 15. Carboloy TP30 (450 SFPM 0.012 IPR. and 0.030 DOC) 

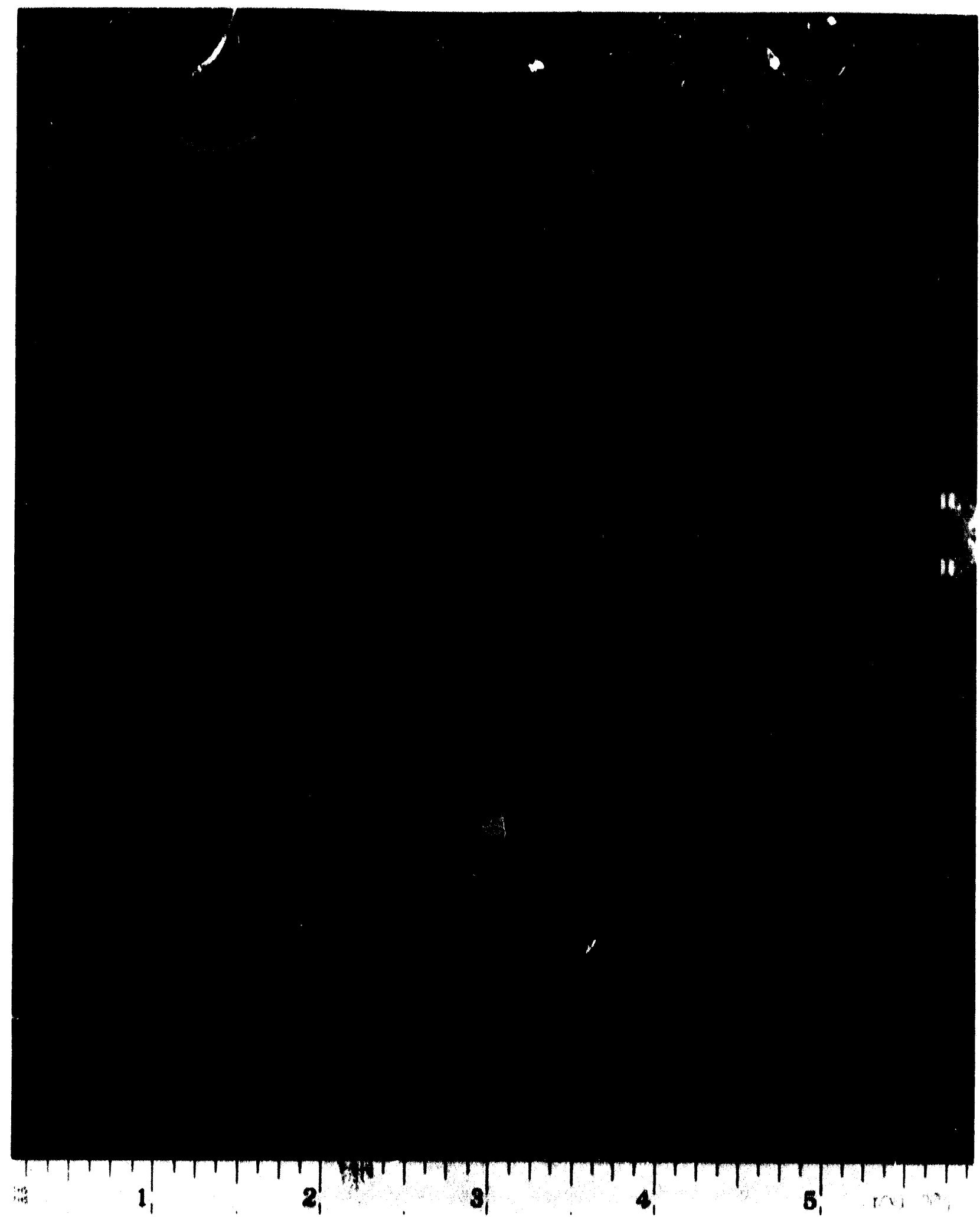

FIOURE 16. Chips Produced by Carboloy TP3O Inserts at Various Cutting Speeds and Feedrates and 0.030 DOC. Feathered chips were produced at higher cutting speeds and feedrates. 


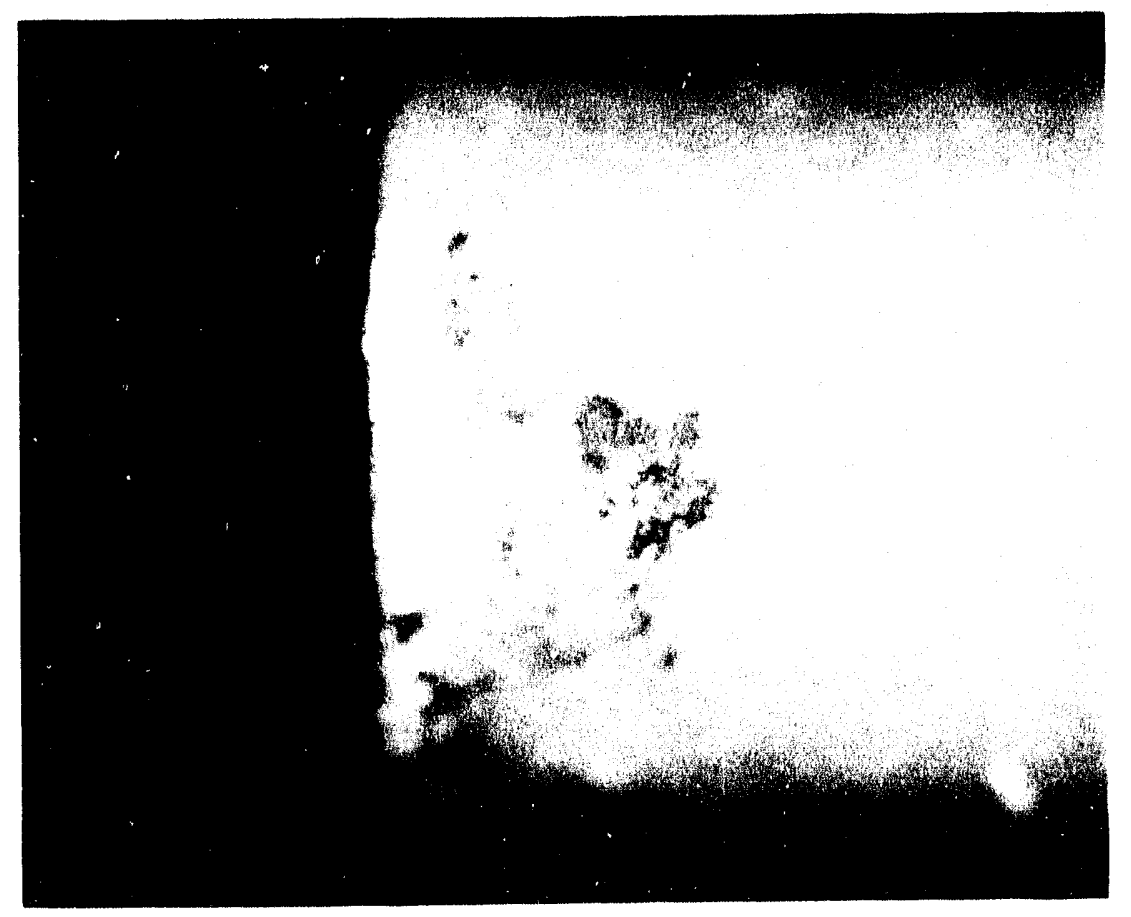

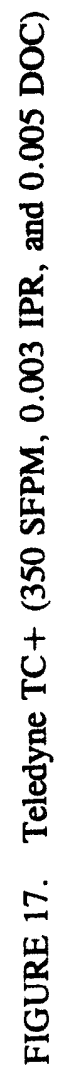

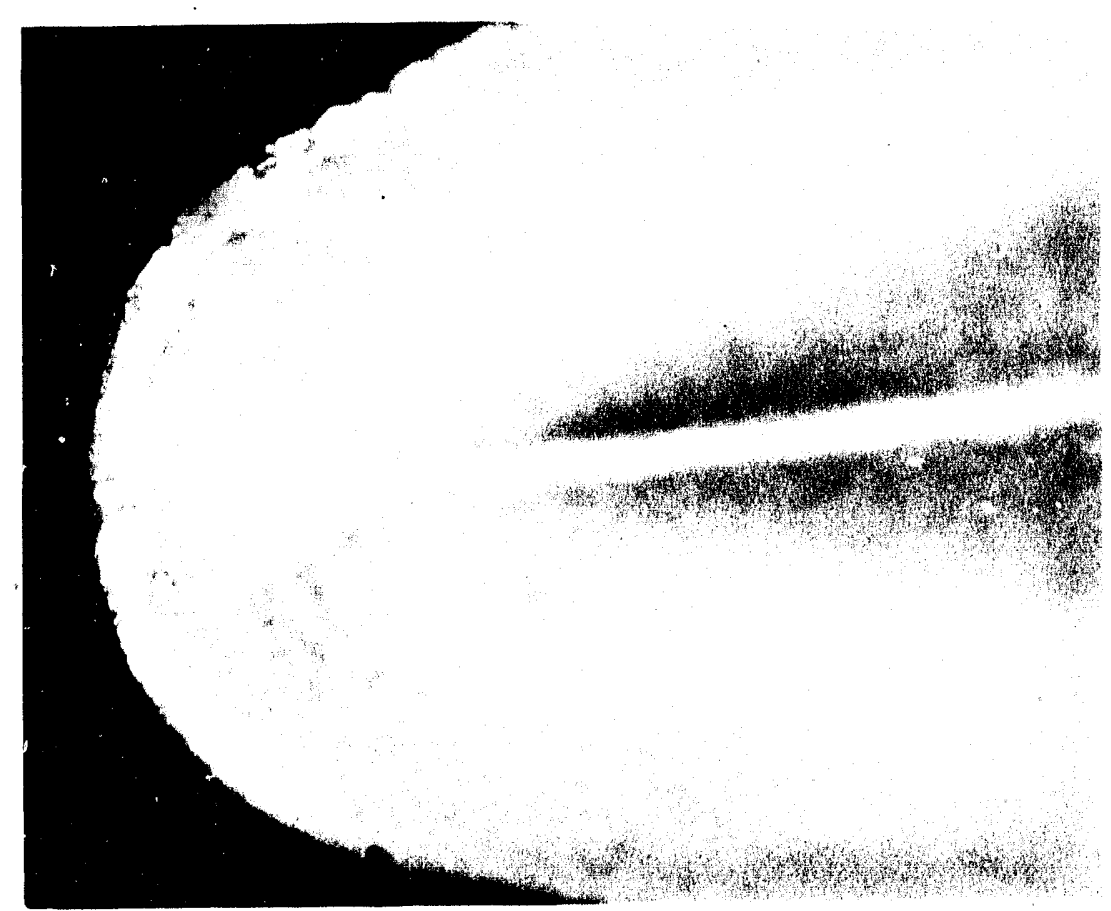



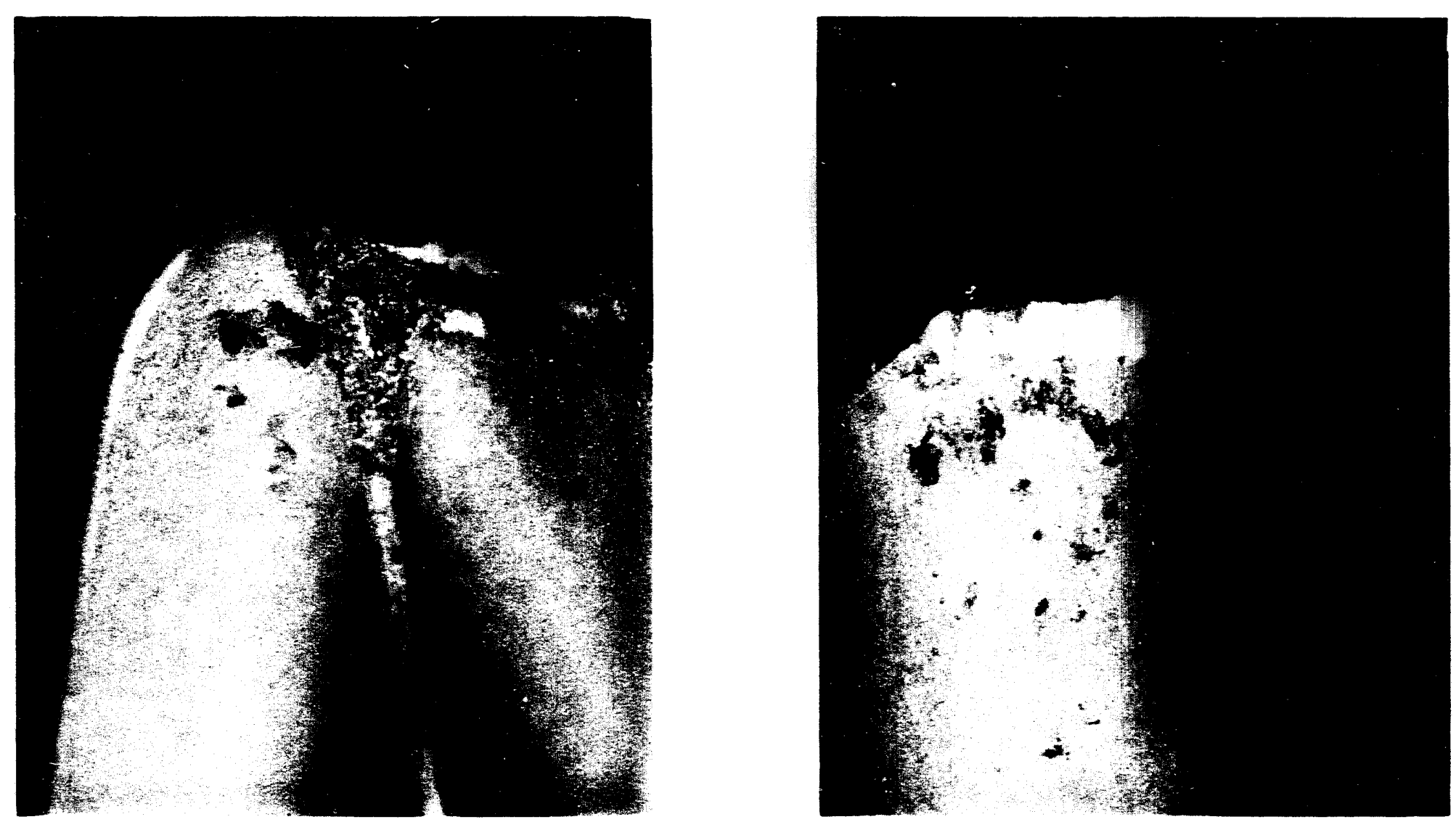

FIGURE 19. Teledyne TC $+(450$ SFPM, 0.006 IPR, and 0.005 DOC) 


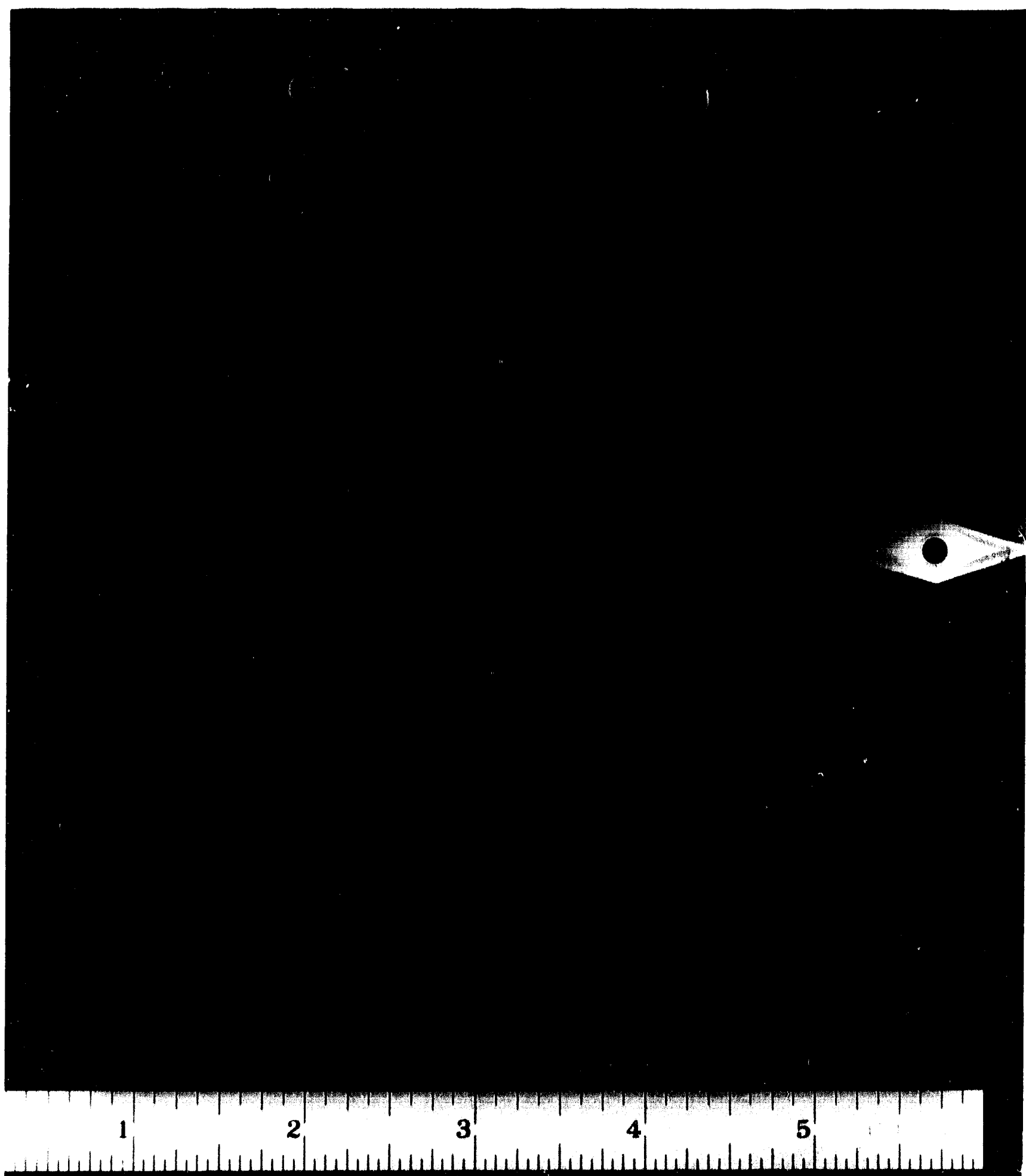

FIGURE 20. Chips Produced by Teledyne TC + Inserts at Various Cutting Speeds and Feedrates and 0.005 DOC. Poor chip control was experienced at all speeds and feeds. 


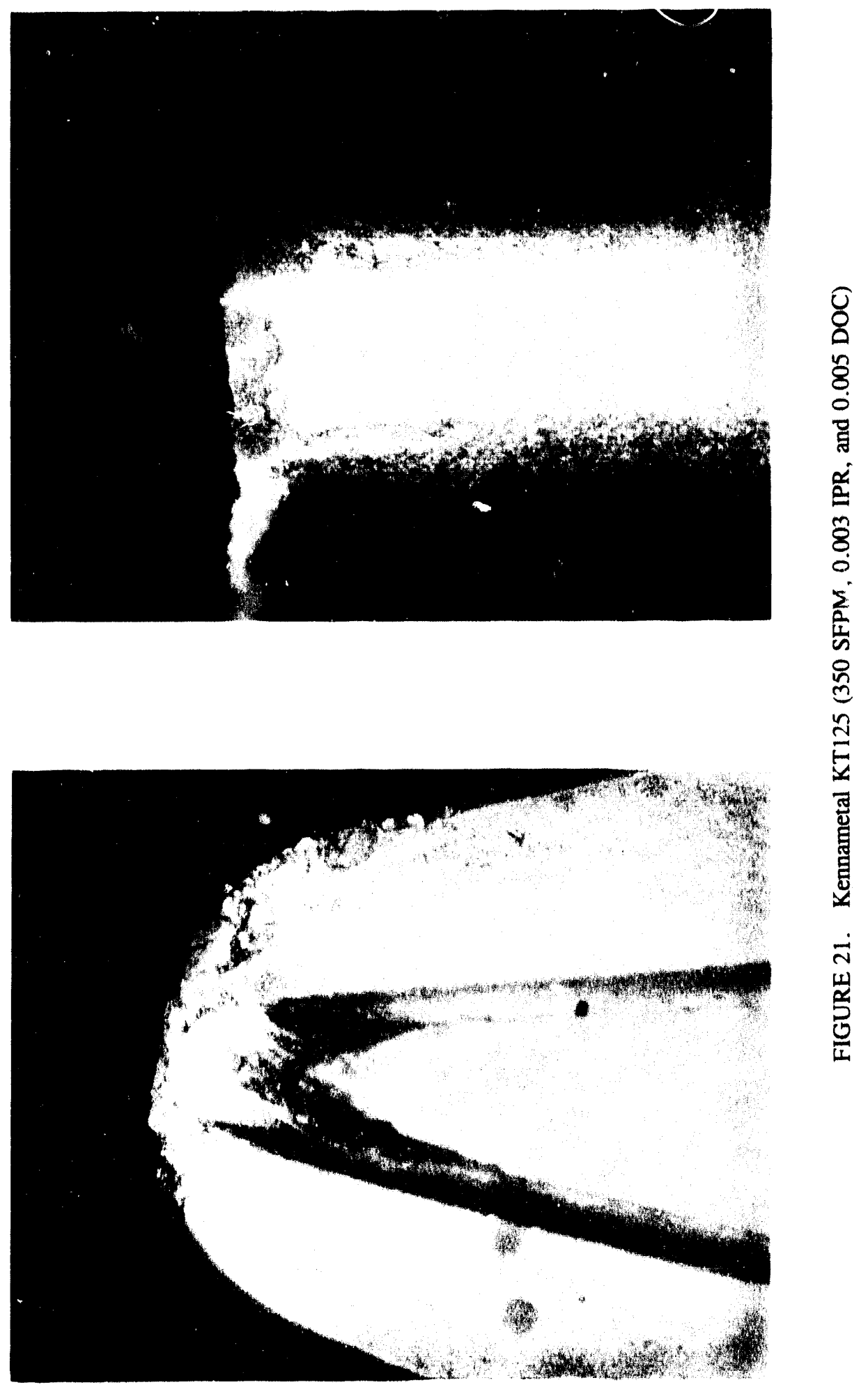



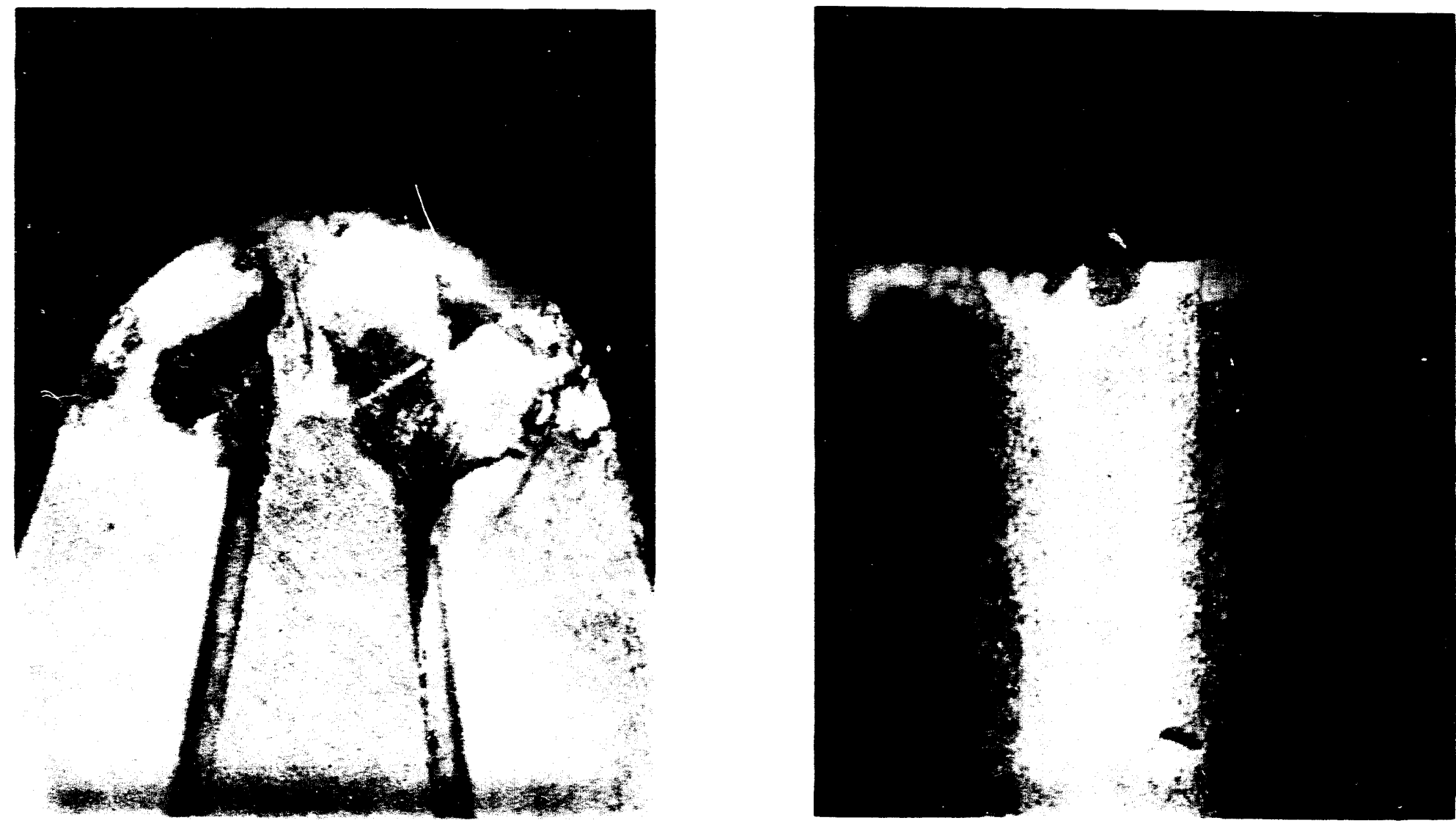

FIGURE 22. Kennametal KT125 (450 SFPM, 0.003 IPR, and 0.005 DOC) 

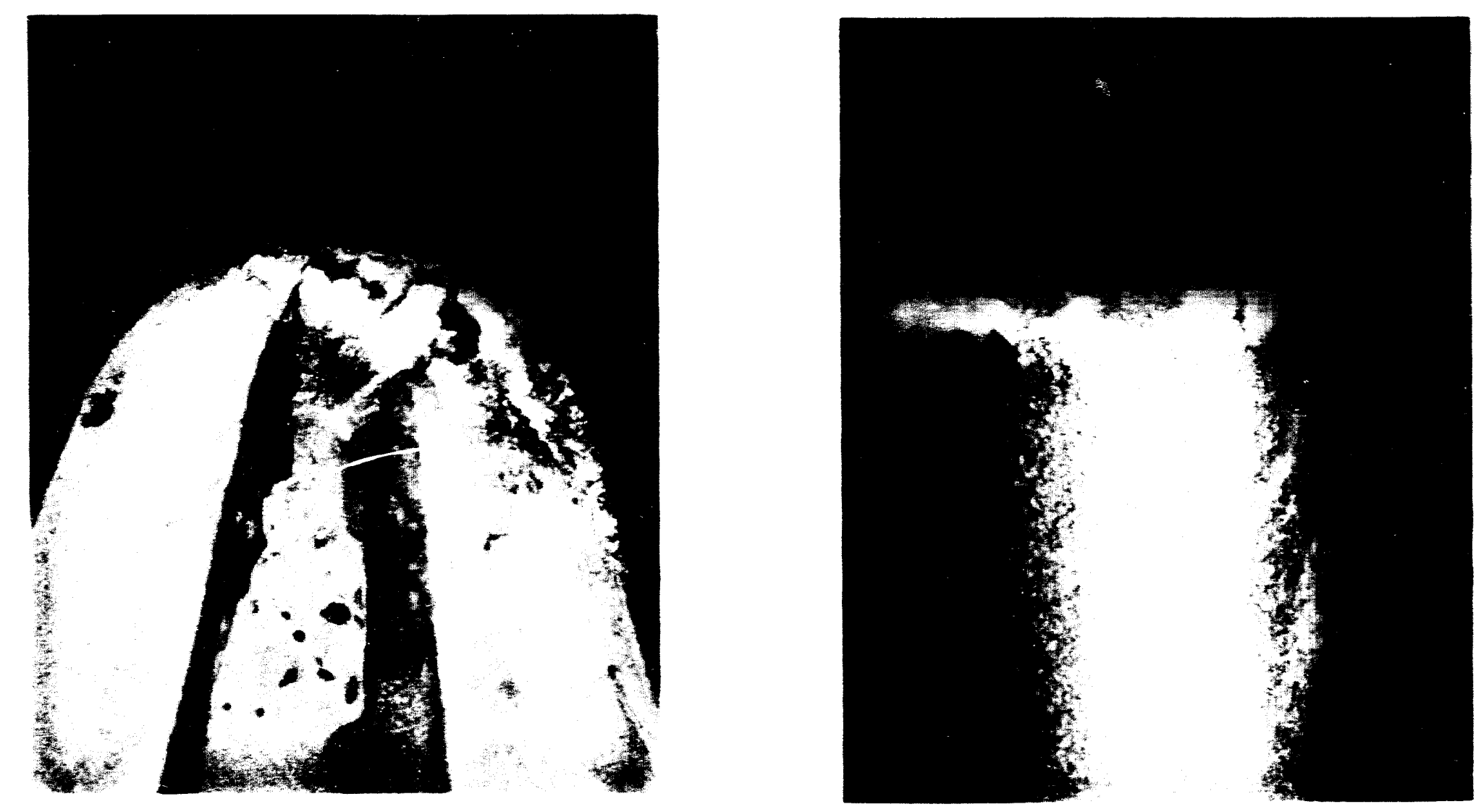

FIGURE 23. Kennametal KT125 (450 SFPM, 0.006 IPR, and 0.005 DOC) 


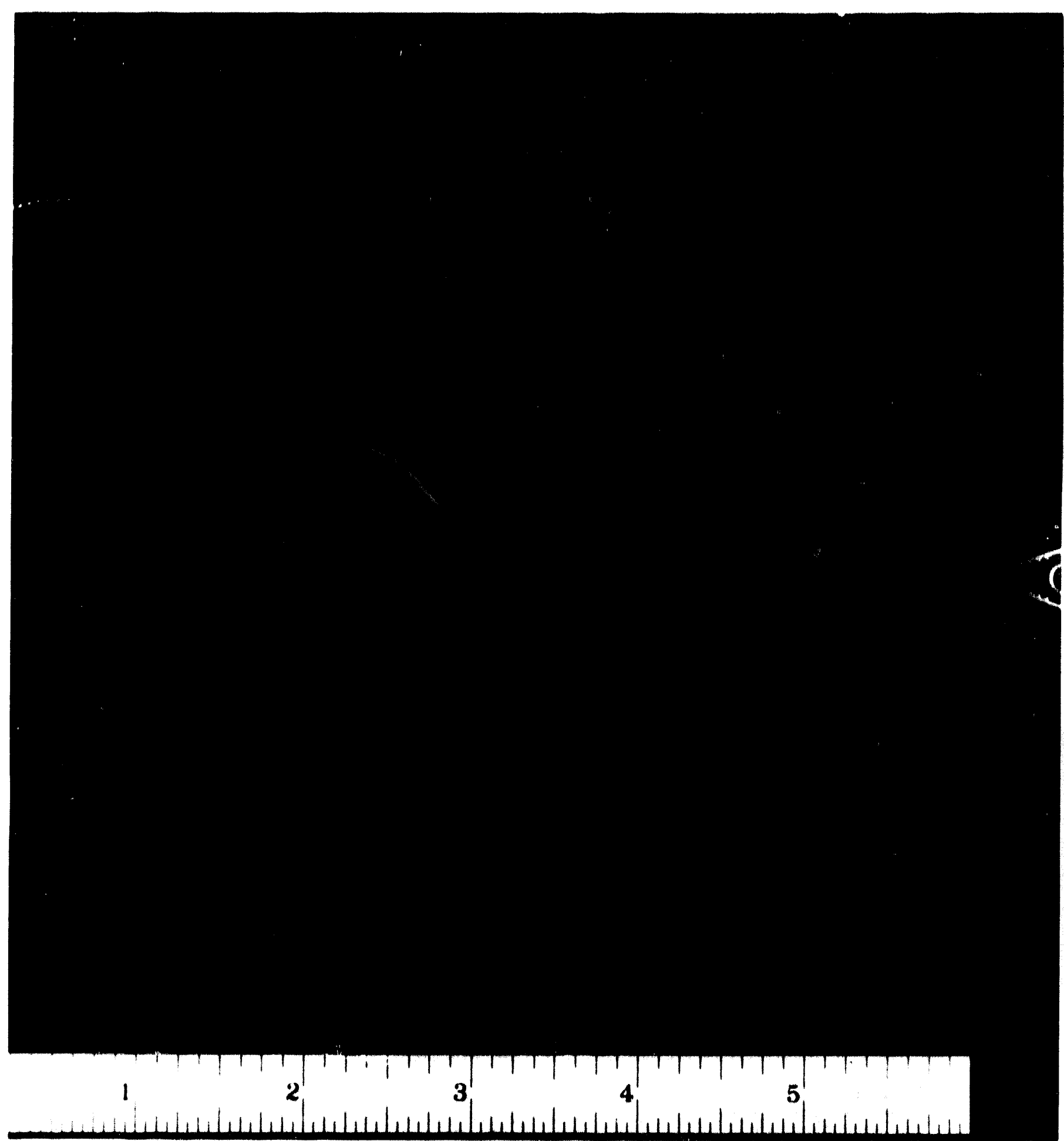

FIGURE 24. Chips Produced by Kennametal KT125 Inserts at Various Cutting Speeds and Feedrates and 0.005 DOC. Fairly good chip control was experienced at all speeds and feeds. 

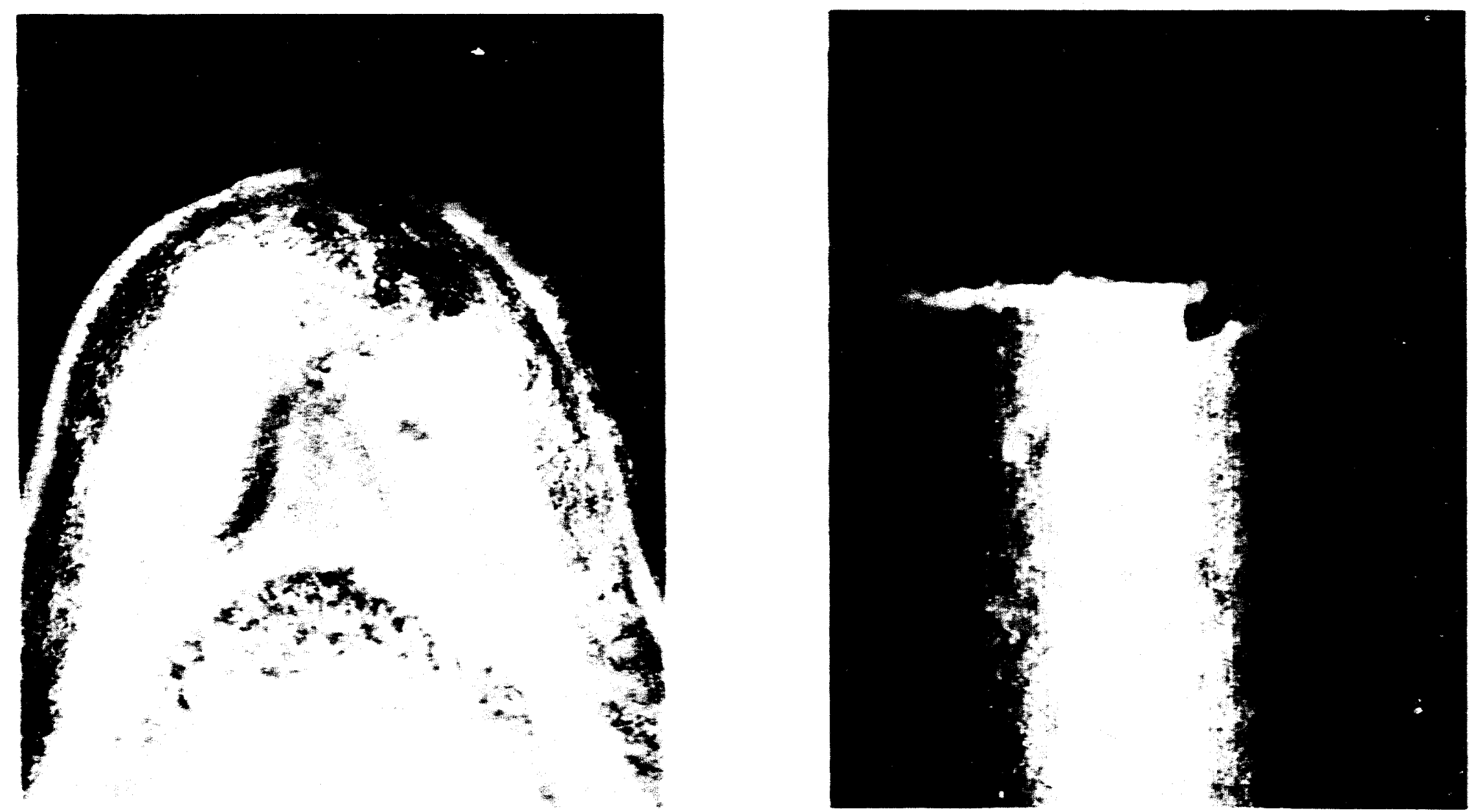

FIGURE 25. Teledyne SD3 (450 SFPM, 0.003 IPR, and 0.005 DOC) 

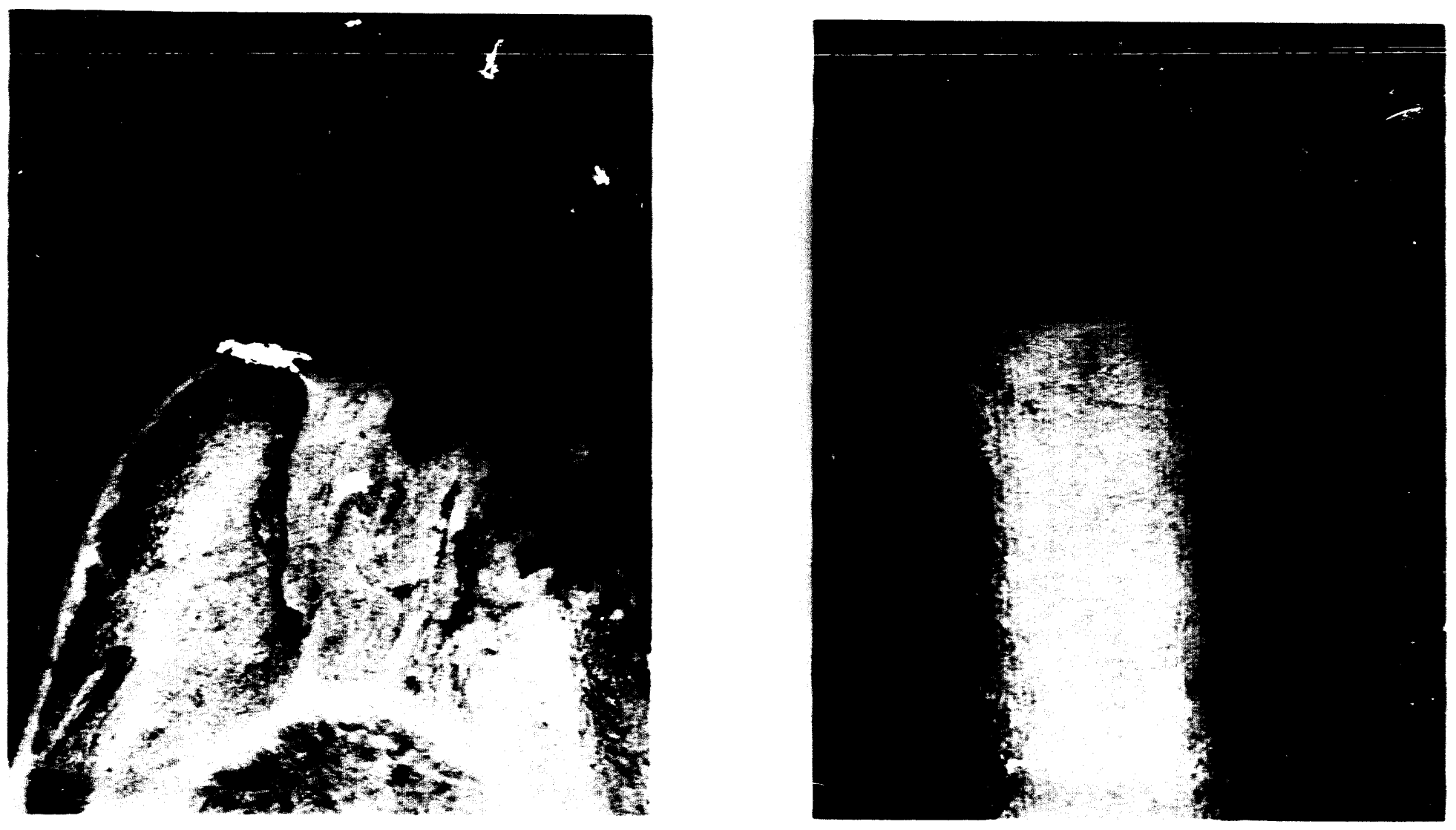

FIGURE 26. Telodyne SD3 (450 SFPM, 0.006 IPR, and 0.005 DOC) 


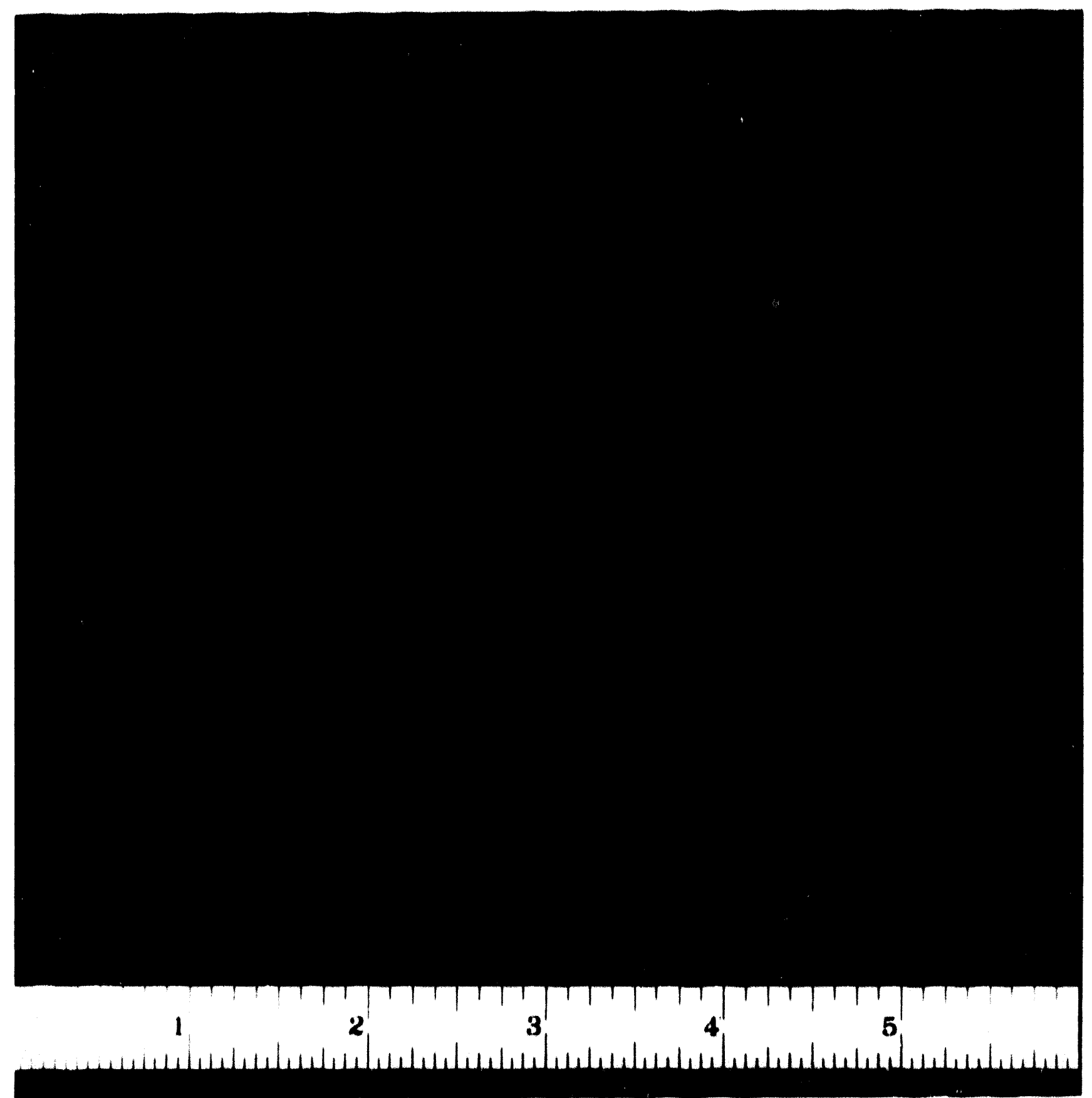

FIGURE 27. Chips Produced by Teledyne SD3 Inserts at Various Cutting Speeds and Feedrates and 0.005 DOC Good Chip control was experienced at higher speeds and feeds. 

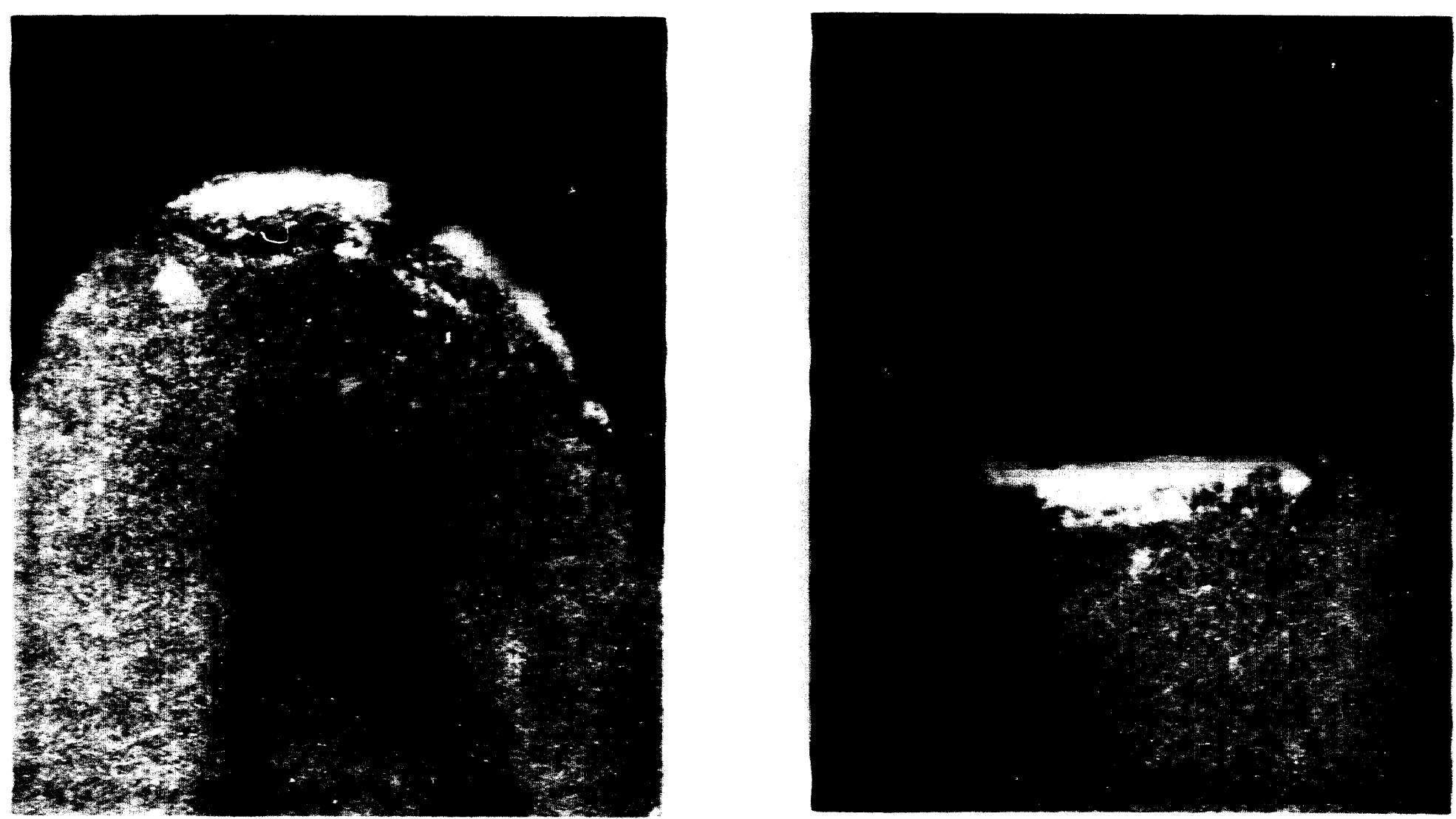

FIGURE 28. Sandvik MF435 (350 SFPM, 0.003 IPR, and 0.005 DOC) 

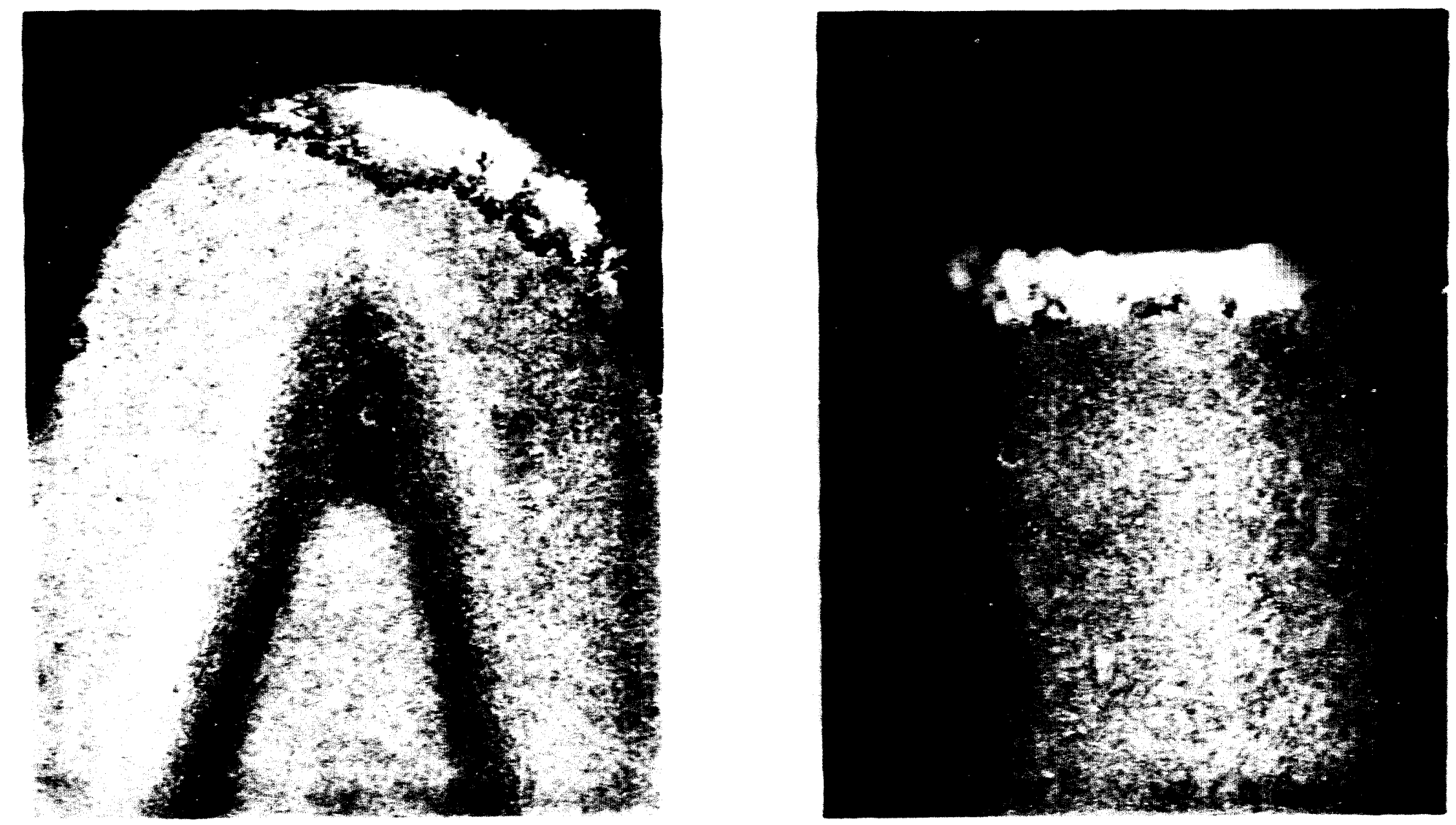

FIGURE 29. Sandvik MF435 (450 SFPM, 0.003 IPR, ad 0.005 DOC) 

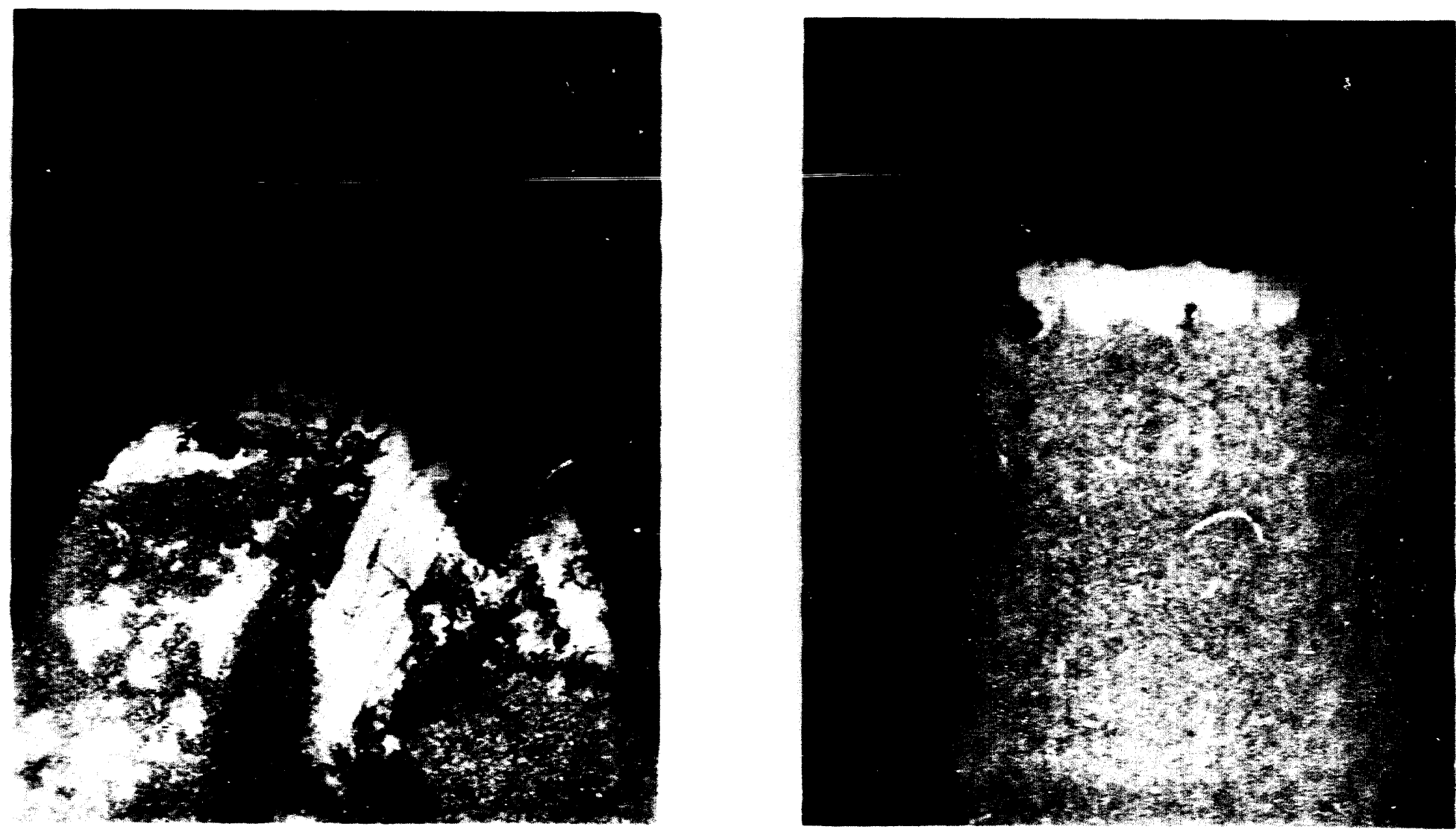

FIGURE 30. Sandvik MF435 (450 SFPM, 0.006 IPR, and 0.005 DOC) 


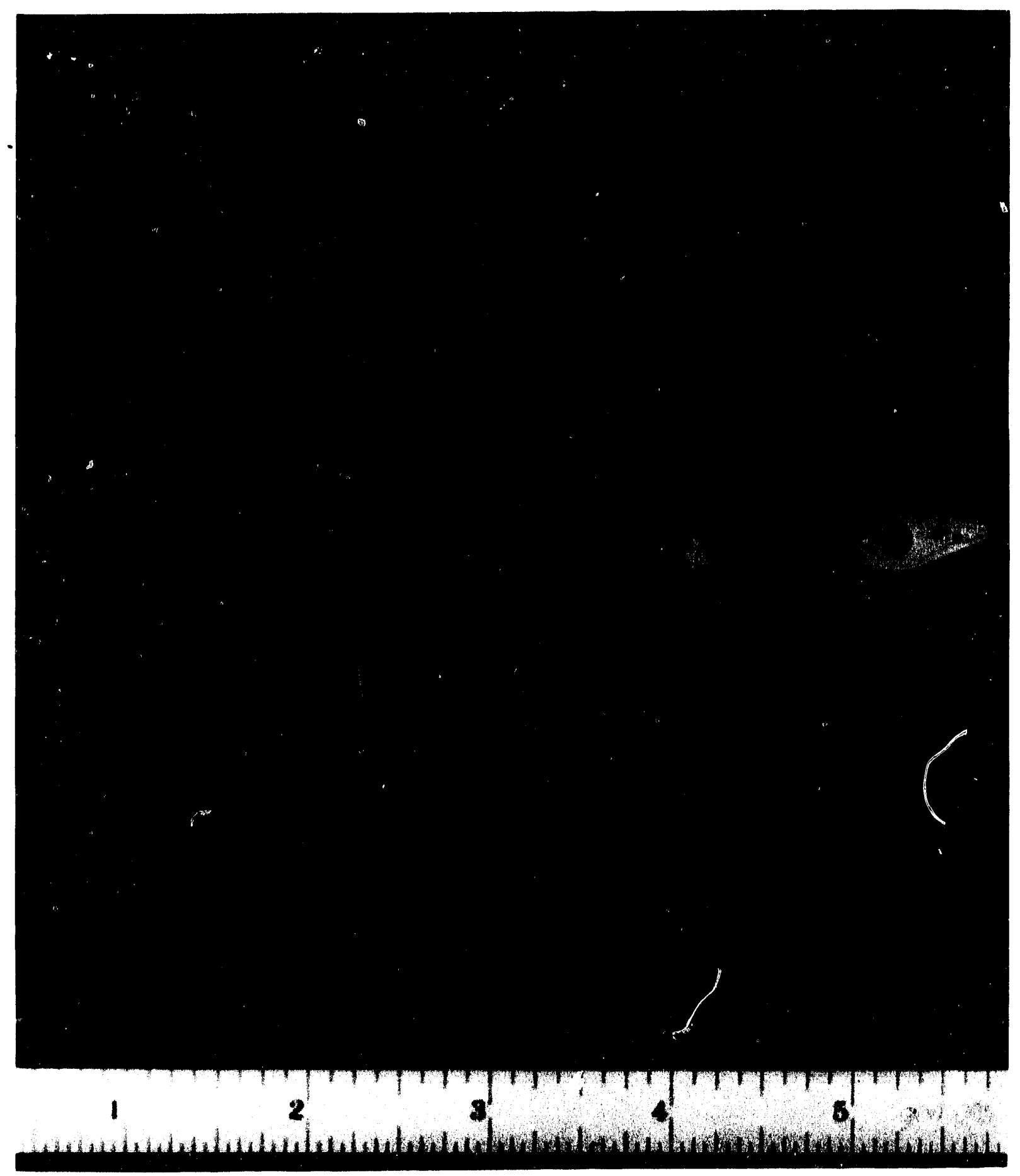

FIGURE 31. Chips Produced by Sandvik MF435 at Various Cutting Speeds and Feedrates and 0.005 DOC. Good chip control was experienced at higher speeds and rates. 
RFP-4627 

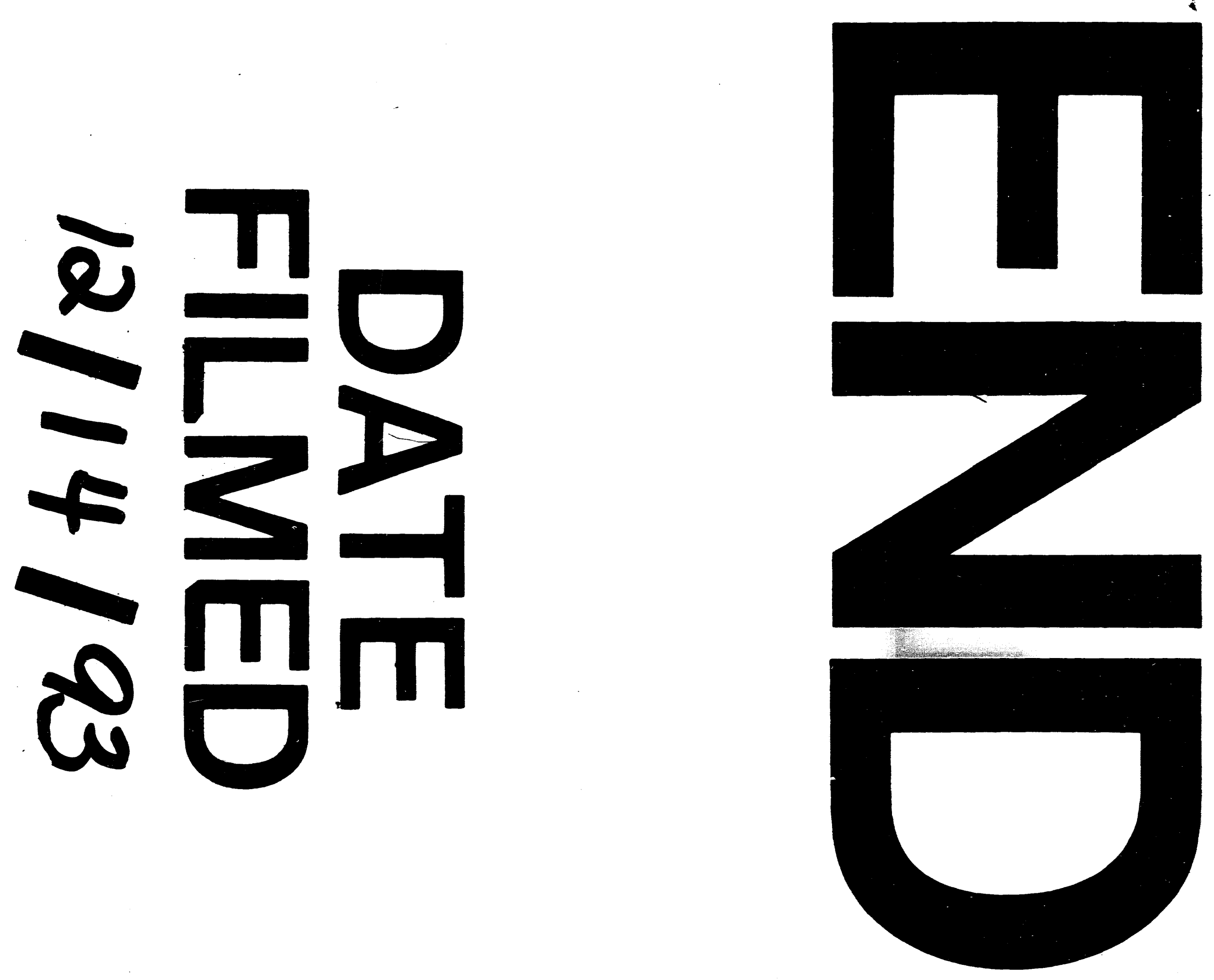
